\title{
EVENTOS DE PRECIPITAÇÃO NA CIDADE DE PELOTAS- RS ASSOCIADOS A PROCESSOS E SISTEMAS SINÓTICOS
}

\author{
NATALIA FEDOROVA ${ }^{1}$, VLADIMIR LEVIT ${ }^{1}$ e MARIA HELENA DE CARVALHO²
}

\author{
${ }^{1}$ Universidade Federal de Alagoas (UFAL), Instituto de Ciências Atmosféricas. \\ Rod. BR 104, km 14, Tabuleiro do Martins, Maceió, AL, Brasil, CEP: 57072-970 \\ E-mail: natalia@dimin.net \\ ${ }^{2}$ Universidade Federal de Pelotas (UFPel), Faculdade de Meteorologia, Departamento de Meteorologia, \\ Caixa Postal 354, Pelotas, RS, Brasil, CEP: 96010-900
}

Recebido Novembro 2005 - Aceito Junho 2006

\begin{abstract}
RESUMO
Este artigo é um estudo observacional dos eventos de precipitação na cidade de Pelotas associados aos sistemas e processos sinóticos durante nove meses de um ano em que ocorreu La Niña, de um ano de El Niño e de um ano normal. Nesta investigação foram encontrados como sistemas sinóticos, as zonas frontais (fria, quente, oclusa, secundária e estacionária) e o processo de ciclogênese. Além disso, as precipitações dentro de uma massa de ar foram associadas a nuvens $\mathrm{Cb}$ e $\mathrm{St}$ e a complexos convectivos de mesoescala (CCM). Foram calculados os valores de precipitação (total-PTM e médiaPM, por mês) gerados pelos diferentes sistemas sinóticos e as variações mensais destes valores foram analisadas. As maiores freqüências de precipitação em frentes frias, quentes, em ondas em frentes frias e em nebulosidades ciclogenéticas ocorreram no ano de El Niño. As precipitações nas frentes oclusas e secundárias foram mais freqüentes no ano de La Niña. As precipitações muita intensas em frentes frias, oclusas, em ondas e em extremidades de frentes frias foram mais freqüentes no ano de El Niño. Os valores máximos de PTM foram produzidos por frentes oclusas e ciclones jovens no ano de El Niño.

Palavras-chave: anos de El Niño e de La Niña; precipitações; sistemas e processos sinóticos.
\end{abstract}

\begin{abstract}
PRECIPITATION EVENTS IN PELOTAS-RS ASSOCIATED WITH SYNOPTIC PROCESSES AND SYSTEMS.

This paper is an observational study of the precipitation events in Pelotas city, associated with synoptic systems and processes during nine months of each of the following years: La Niña, El Niño and Normal. The synoptic systems found in this study are: the frontal zones (cold, warm, occluded, secondary and stationary fronts) and the cyclogenesis processes. The precipitations inside the air masses were associated with $\mathrm{Cb}$ and St clouds and with mesoscale convective complexes (MCC). The precipitation values (total-TMP and average-AP, per month) produced by the different synoptic systems were calculated and the mensal variations of these values were analysed. The highest precipitations frequencies associated with cold and warm fronts, waves and cyclogenetic cloudiness were detected in the El Niño year. The precipitations caused by occluded and secondary fronts were more frequent in the La Niña year. Very heavy precipitations associated with cold and occluded fronts, waves and cold front extremities were found more frequently during the El Niño year. The greatest TMP values were produced by occluded fronts and by young cyclones in the El Niño year.

Keywords: La Niña and El Niño years; precipitation; synoptic systems and processes.
\end{abstract}




\section{INTRODUÇÃO}

A previsão a curto da precipitação é um dos elementos principais no trabalho diário dos meteorologistas nos diferentes centros de previsão. Por isso, é muito importante o estudo dos sistemas e processos sinóticos associados.

O comportamento das precipitações mensais em Pelotas durante os eventos El Niño e La Niña no período de 1950 a 1997 foi estudado por Sansigolo et al. (2000). Os autores concluíram que a influência do fenômeno El Niño no regime de precipitação é pequena e restrita ao segundo trimestre do ano, enquanto a do La Niña é significativamente superior, embora pequena, na maior parte do ano.

Pelos resultados de Ropelewski e Halpert $(1987,1989)$ os períodos com oceano frio (temperatura da superfície do mar abaixo da normal, ou evento La Niña) na parte central do Pacífico estão associados com anomalias secas no sul e sudoeste da América do Sul. No ano de El Niño a situação é inversa, ou seja, o oceano quente está associado com anomalia úmida nestas regiões.

Pisciottano et al. (1994) encontraram precipitações acima da média no Uruguai, de novembro a janeiro, nos anos de El Niño. Nos anos com altos valores de índice de Oscilação Sul foi observada uma tendência de ocorrência de precipitações abaixo do normal no período de outubro até dezembro. No período de março a julho foram observadas precipitações acima do normal em anos seguintes a anos de El Niño e precipitações abaixo do normal em anos posteriores a anos de La Niña.

O número de CCM's no norte da Argentina e Paraguai em anos de El Niño é duas vezes maior do que em anos normais. Pelos dados de Velasco e Fritsch (1987), este fato está ligado à intensificação da corrente de jato subtropical nestes anos. $\mathrm{Na}$ opinião destes autores, o aumento das precipitações no Sul do Brasil nos anos de El Niño ocorre devido à intensificação da atividade dos CCM's.

Segundo Tanaka e Nishizawa (1983), em anos com circulação de Hadley mais intensa foram encontradas precipitações acima do normal no sul do Brasil. Quando esta circulação era fraca, as precipitações observadas na mesma região estiveram abaixo do normal. A circulação de Hadley intensa intensificou-se devido a um ciclone no nível de $850 \mathrm{hPa}$ localizado em torno de $28^{\circ} \mathrm{S}$ e $65^{\circ} \mathrm{W}$.

De acordo com Satyamurty et al. (1998), em ano de El Niño a corrente de jato subtropical posiciona-se próximo da latitude de $30^{\circ} \mathrm{S}$, as frentes frias não penetram ao norte desta latitude e a convecção intensa sobre o Paraguai, nordeste da Argentina, Uruguai e Sul do Brasil gera precipitação acima da média.

Utilizando dados de seis estações meteorológicas do Rio Grande do Sul para 41 anos (1935-1975), Rao e Hada (1990) estudaram as correlações (usando coeficientes de correlação) entre a precipitação e a Oscilação Sul. Quase todos os coeficientes de correlação foram negativos. Na primavera (setembro, outubro e novembro) as correlações foram mais significativas, com valor de $-0,65$. Para todo o Brasil foram usados dados para 21 anos e os autores concluíram que a correlação entre o índice de Oscilação do Sul e a precipitação é pequena sobre a maior parte do Brasil; todavia no Rio Grande do Sul ela é significativa.

As características do El Niño e sua influência nas anomalias de precipitação no Brasil foram discutidas por Kousky e Cavalcanti (1984). Segundo estes autores, os eventos de El Niño são associados com grandes variações na configuração do escoamento troposférico; as correntes de jato são intensas e as situações de bloqueio são mais freqüentes. Durante o evento El Niño de 1982-1983 observou-se alto índice de precipitação acompanhada de enchentes em várias regiões do sul do Brasil. Em algumas estações, a precipitação de apenas um mês, julho, foi comparada à média climatológica de sete meses acumulados. Usando imagens de satélite e dados de superfície eles verificaram que a elevada quantidade de precipitação ocorrida no Sul do Brasil em 1983 esteve associada a sistemas frontais que permaneceram durante longo tempo e com muita atividade sobre a região. De acordo com Kousky e Cavalcanti, normalmente, no inverno, as frentes frias avançam rapidamente para norte e leste, porém, durante os meses de outono e inverno de 1983, estes sistemas frontais avançaram para norte até atingir a latitude de $30^{\circ} \mathrm{S}$, onde se encontra a corrente de jato subtropical (JST), a qual é intensificada durante os anos de El Niño. Então, as frentes tiveram uma tendência a permanecer quase estacionárias um pouco ao norte da latitude do JST. Ao longo e ao sul dessas frentes, houve o desenvolvimento de forte atividade convectiva, a qual contribuiu para a precipitação excessiva nas regiões Sul e Sudeste do Brasil.

As precipitações intensas na região de Pelotas causam efeitos negativos em diversos setores da economia e a sociedade em geral sofre enormes prejuízos. O padrão de distribuição espacial das chuvas intensas para durações variando de 3 a 24 horas em Pelotas e região circunvizinha (regiões central, sul e leste do Estado do Rio Grande do Sul, RS) foi estudada por Goulart (1992). Foram selecionadas as chuvas intensas, ou seja, os eventos cuja precipitação média na área abrangida excede $12,5 \mathrm{~mm}$ e que uma ou mais estações meteorológicas tenha registrado uma quantidade de chuva igual ou superior à estimada. De acordo com este critério foram selecionados 24 eventos no período compreendido entre 1954 e 1984 . A análise das alturas pluviométricas com duração de chuva mostra que a precipitação máxima para o período de $1 / 2$ hora foi $34,7 \mathrm{~mm}$; para 2 e 3 horas foram quase iguais, 50,2 e $54,9 \mathrm{~mm}$, respectivamente; para 24 horas atingiram $85,2 \mathrm{~mm}$. Foi estimado o fator de redução da precipitação pontual em função da área de abrangência. 
O mesmo autor enfatizou a necessidade de desenvolvimento de uma rede de postos pluviométricos mais densa e com distribuição geográfica mais uniforme. Em conseqüência da má distribuição geográfica e da baixa densidade, na opinião do autor, os valores do fator de redução da precipitação pontual e os da precipitação média decresceram com o aumento da área de abrangência considerada. Para uma mesma área foi verificado que a redução da precipitação pontual diminuiu sistematicamente com o aumento da duração da chuva de 3 até 12 horas. A partir daí, a redução da precipitação pontual voltou a subir até a duração de 24 horas. Este fato, na opinião do autor, talvez seja conseqüência da redução sistemática do número de eventos que puderam ser considerados na análise.

Os principais sistemas meteorológicos associados a um caso de chuvas intensas com enchentes na região do Vale do Itajaí, em Santa Catarina, são descritos em Severo et al. (1994). Nos altos níveis a corrente de jato e o centro de velocidades máximas (c.v.m.) geraram circulações transversais, criando áreas de divergência nas proximidades do c.v.m. Com isso, a atividade convectiva foi iniciada em função da divergência a leste do eixo do cavado nos altos níveis e da convergência de umidade nos níveis mais baixos. O rápido deslocamento do vórtice nos baixos níveis aumentou a instabilidade convectiva. O transporte de umidade desde o Brasil Central, junto com aquele associado à circulação anticiclônica do Atlântico, para a região de divergência nos altos níveis, contribuiu para o desenvolvimento convectivo. Os campos de advecção de temperatura potencial equivalente para $850 \mathrm{hPa}$ representam muito bem este transporte.

A identificação dos sistemas sinóticos (21 casos) na baixa e alta troposfera, que geraram precipitações intensas no Vale do Itajaí, Santa Catarina (SC), é apresentada no trabalho de Severo (1994). Estes casos foram divididos em cinco grupos: 1) sistema frontal estacionário, às vezes com ondas; 2 ) vórtice ciclônico nos altos níveis; 3 ) nebulosidade convectiva associada com circulações transversais da corrente de jato com curvatura anticiclônica sobre o Rio Grande do Sul; 4) desenvolvimento convectivo muito intenso, associado com difluência no escoamento zonal nos altos níveis e avanço do sistema frontal do RS até o norte de $\mathrm{SC}$ e 5) sistema frontal que passa pela região sul do Brasil e depois retrocede como frente quente. Um fluxo de ar úmido que se origina no Brasil Central é a fonte alimentadora da convecção que é disparada quando mecanismos dinâmicos, tais como sistemas frontais e vórtices ciclônicos, aproximam-se de Santa Catarina.

Uma análise climatológica da precipitação em Pelotas foi feita por Silva e Amaral (1987) e foram apresentados os valores totais e máximos em cada uma das 73 pêntadas do ano. Utilizando um arquivo de dados de 1900 a 1951, foram elaboradas as tabelas de probabilidades pentadais, totais e máximas, usando as transformações raiz cúbica e raiz quinta. Os resultados das probabilidades foram estabelecidos para as probabilidades condicionais $\left(\mathrm{P}_{\mathrm{c}}\right)$ em níveis decrescentes de $\mathrm{P}_{\mathrm{c}}=0,99$ a $\mathrm{P}_{\mathrm{c}}=0,01$, em cada uma das pêntadas do ano e foram verificados para o período de 1951 a 1980. A concordância entre os valores observados e os calculados foi bastante satisfatória, donde se pode concluir que as séries de observações são homogêneas.

De acordo com Goulart (1992), o mês mais chuvoso é setembro e o mais seco é abril. Estes meses apresentam precipitações equivalentes a $10,1 \%$ e $7,3 \%$ do total anual em Pelotas. Pelos resultados de Assis os dias chuvosos em Pelotas apresentam uma distribuição bem uniforme ao longo do ano (Este resultado da dissertação de doutorado de Assis, 1991, foi citado em Goulart, 1992).

As correlações entre as precipitações e os padrões de circulação na América do Sul foram estudadas por Kousky e Cavalcanti (1988). Foram utilizadas as componentes do vento no nível de $250 \mathrm{hPa}$ e a radiação de ondas longas emergente para os anos de janeiro de 1979 até dezembro de 1986. A resolução dos campos foi de $7,5^{\circ} \times 7,5^{\circ}$ para as latitudes e longitudes nas regiões tropicais e subtropicais da América do Sul e oceanos adjacentes. Foram encontradas correlações entre cavados nos altos níveis e a nebulosidade, principalmente, nas latitudes médias. O primeiro e o terceiro padrões das funções ortogonais empíricas mostraram anomalias equatoriais de leste (oeste) e circulação anticiclônica (ciclônica) anômala, as quais estavam associadas com anomalias negativas (positivas) da radiação de ondas longas. O primeiro e o terceiro padrões de funções ortogonais empíricas exibem variabilidade temporal em ambas as escala interanual e intra-sazonal.

A análise das interações entre sistemas frontais na América do Sul e a convecção tropical na Amazônia foi feita no trabalho de Oliveira (1986) e também é apresentada em Satyamurty et al. (1998). Eles verificaram que esta interação ocorre predominantemente quando os sistemas frontais estão associados a cavados que se estendem dos baixos aos altos níveis, com inclinação preferencial noroeste-sudeste. Há forte advecção de ar frio e subsidência no lado polar da faixa de nebulosidade convectiva associada e advecção de ar quente e movimento ascendente na região desta faixa. A climatologia (durante dez anos, de 1975 até 1984) das penetrações frontais na América do Sul (para 4 faixas de latitudes: de 40 até $35^{\circ} \mathrm{S}$, de 35 até $25^{\circ} \mathrm{S}$, de 25 até $20^{\circ} \mathrm{S}$ e de 20 até $05^{\circ} \mathrm{S}$ ) e da atividade convectiva na Amazônia foi feita por imagens do satélite GOES. As penetrações dos sistemas frontais foram observadas em todas as faixas de latitude durante todos os anos. Foi notado que a região entre 25 e $20^{\circ} \mathrm{S}$ é o limite de penetração meridional para a maioria dos sistemas frontais. Os sistemas frontais são mais freqüentes na faixa de 40 até $35^{\circ} \mathrm{S}$ (nove por mês), e mais raros ao norte de $20^{\circ} \mathrm{S}$ (dois por mês). Notou-se 
que a trajetória dos sistemas frontais, quando se encontravam ao sul de $40^{\circ} \mathrm{S}$, era predominantemente zonal. Entre 35 e $40^{\circ} \mathrm{S}$ algumas frentes ganham trajetória mais meridional e atingem latitudes mais baixas, enquanto outras prosseguem numa direção mais zonal.

O objetivo deste trabalho é o estudo das precipitações (muito intensas, intensas, médias e fracas) na cidade de Pelotas geradas por diferentes sistemas e processos sinóticos durante nove meses de um ano em que ocorreu La Niña, de um ano de El Niño e de um ano normal e a análise da variação mensal destas precipitações.

\section{DADOS E METODOLOGIA}

\subsection{Análise das precipitações}

Este estudo foi realizado para nove meses de um ano de La Niña (de julho de 1998 até março de 1999), de um ano de El Niño (de julho de 1997 até março de 1998) e de um ano Normal, ou seja, no qual os fenômenos El Niño e La Niña não foram registrados (de julho de 1996 até março de 1997). A descrição detalhada do período analisado foi feita em Fedorova et al. (2000a).

Foram utilizados dados diários de precipitação da estação meteorológica do Centro de Pesquisas Meteorológicas (CPMET) da Universidade Federal de Pelotas e da Estação Agroclimatológica de Pelotas - Convênio Embrapa/UFPel (Agr). Estas duas estações localizam-se em pontos opostos da cidade de Pelotas e a distância entre elas é, aproximadamente, $20 \mathrm{~km}$.

Primeiramente foram comparados os valores das quantidades de precipitação nestas duas estações; calculadas as diferenças das mesmas e obtidos os valores máximos das diferenças. As diferenças entre a quantidade de precipitação no CPMET e na Agr podem ser vistas na Tabela 1, na qual foram identificadas por $D$. Com base nestes valores $\mathrm{D}$ foram calculados valores médios (Dmed na Tabela 1) e encontradas as diferenças máximas (Dmax na mesma Tabela). Além disso, foram encontrados os valores máximos de precipitação por mês ( Vmax na Tabela 1), ou seja, Vmax é o valor da precipitação durante o evento em que este valor foi máximo em cada um dos meses analisados.

Foram determinados os dias em que foram registradas precipitações nas duas estações e aqueles em que ocorreu precipitação somente em uma delas. É necessário ressaltar que não são realizadas observações na estação meteorológica do CPMET nos fins de semana e nos feriados. Por isso, também foram verificados dias com precipitação na estação AGR, para os quais não existiam dados na estação do CPMET. Para a análise das situações sinóticas foram escolhidos os dias em que as precipitações foram observadas em uma ou nas duas estações.
Os valores de quantidade de precipitação, assim como o número de dias com precipitação em Pelotas são considerados neste trabalho como características da precipitação.

Foram analisados também os períodos de tempo (Perío$d o s)$ em que as precipitações foram observadas em dias consecutivos nas duas ou em uma das estações. Estes Períodos são uma das características de duração das precipitações.

\subsection{Análise das situações sinóticas associadas às precipitações}

As situações sinóticas foram determinadas para os dias em que as precipitações foram registradas apenas numa das estações meteorológicas (CPMET ou Agr) e, também, nas duas estações meteorológicas. A identificação das situações sinóticas foi realizada para os mesmos meses dos anos de La Niña, El Niño e Normal, citados no item 2.1.

A identificação da situação sinótica foi feita usando-se dados de satélite no canal infravermelho, da mesma maneira como foi descrito em Fedorova e Carvalho (2000), Fedorova et al. (1999, 2000a) e, também, em Fedorova e Bakst (1999a, 1999b, 1996), ou seja, foram identificadas as zonas frontais e os vórtices ciclônicos, os quais estavam associados com as precipitações na cidade. Para os dias em que não foi identificado nenhum sistema sinótico mencionado acima, foram registrados dados sobre os tipos de nuvens. Durante os meses dos anos de La Niña e de El Niño, foram feitas observações dos tipos de nuvens na estação meteorológica do CPMET. Para o ano normal, devido à ausência de dados observacionais, os tipos de nuvens foram identificados nas imagens de satélite nos canais infravermelho, vapor d'água e visível, de acordo com as descrições em Andersen (1973), Conway (1997) e Rao et al. (1990).

Para a identificação da situação sinótica em todo o período de estudo e, também, dos tipos de nuvens no ano normal foi usado o banco de dados de satélite do CPMET. Devido à ausência de dados neste arquivo em muitos períodos, também foi usado o banco de dados do CPTEC, o qual está disponível na página do INPE na Internet (http//:www. dsa.inpe.br/produtos.htm). Foram analisados os dados do satélite GOES. Nos casos para os quais os dados não estavam disponíveis nesta página, foram utilizados os dados do satélite METEOSAT, obtidos no mesmo site. É importante ressaltar que a utilização das imagens de diferentes satélites não influenciou na identificação dos sistemas sinóticos devido à localização da região de estudo estar bastante centralizada em todas as imagens.

Todas as situações sinóticas foram divididas em três grupos, ou seja, as precipitações foram associadas com: 1) zonas frontais, 2) ciclones e 3) uma massa de ar (Tabela 2). 
Tabela 1 - Quantidade de dias com precipitação e quantidade de precipitação nas estações do CPMET (CP) e Agrometeorológica de Pelotas (Agr) para os meses dos anos de La Nina, El Nino e Normal.

\begin{tabular}{|c|c|c|c|c|c|c|c|c|c|c|c|}
\hline \multirow{3}{*}{ Mês } & \multicolumn{5}{|c|}{ Quantidade de dias com precipitação } & \multicolumn{6}{|c|}{ Quantidade de precipitação } \\
\hline & \multirow{2}{*}{$\mathrm{C}+\mathrm{A}$} & \multirow{2}{*}{$\mathbf{C P}$} & \multirow{2}{*}{ Agr } & \multirow{2}{*}{$\mathbf{A} / \mathbf{S d}$} & \multirow{2}{*}{$\Sigma$} & \multicolumn{2}{|c|}{$\sum$ mês } & \multicolumn{2}{|c|}{ Vmax } & \multicolumn{2}{|c|}{ D } \\
\hline & & & & & & $\mathbf{C P}$ & Agr & $\mathbf{C P}$ & Agr & Dmed & Dmax \\
\hline \multicolumn{12}{|c|}{ La Niña } \\
\hline 1 & 5 & 0 & 7 & 1 & 13 & 157,4 & 167,4 & 71,6 & 44,4 & 14,6 & 36,2 \\
\hline 2 & 2 & 2 & 1 & 2 & 7 & 48,8 & 51,8 & 30,0 & 20,4 & 10,6 & 30,0 \\
\hline 3 & 4 & 3 & 6 & 3 & 16 & 63,2 & 46,4 & 25,3 & 10,4 & 3,6 & 11,6 \\
\hline 7 & 6 & 1 & 3 & 0 & 10 & 114,7 & 124,0 & 35,3 & 46,6 & 12,3 & 34,1 \\
\hline 8 & 9 & 1 & 2 & 0 & 12 & 310,3 & 269,8 & 107,4 & 74,8 & 11,8 & 32,6 \\
\hline 9 & 6 & 3 & 4 & 1 & 14 & 116,8 & 119,2 & 26,3 & 22,2 & 7,4 & 17,4 \\
\hline 10 & 2 & 0 & 3 & 1 & 6 & 4,2 & 10,2 & 2,1 & 3,6 & 1,2 & 3,6 \\
\hline 11 & 4 & 1 & 4 & 2 & 11 & 56,8 & 63,2 & 35,3 & 22,4 & 7,0 & 21,5 \\
\hline 12 & 6 & 3 & 6 & 1 & 16 & 116,3 & 108,5 & 57,4 & 38,6 & 9,9 & 38,6 \\
\hline$\Sigma$ & 44 & 14 & 36 & 11 & 105 & 988,6 & 960,5 & & & 8,7 & \\
\hline \multicolumn{12}{|c|}{ EI Niño } \\
\hline 1 & 7 & 3 & 4 & 6 & 20 & 202,1 & 188,4 & 41,0 & 51,2 & 14,4 & 33,4 \\
\hline 2 & 9 & 0 & 4 & 2 & 15 & 291,3 & 301,0 & 97,4 & 74,0 & 14,9 & 31,1 \\
\hline 3 & 8 & 5 & 4 & 1 & 18 & 210,7 & 158,8 & 71,1 & 53,4 & 11,7 & 37,4 \\
\hline 7 & 7 & 0 & 3 & 0 & 10 & 160,5 & 131,9 & 103,2 & 53,4 & 12,5 & 49,8 \\
\hline 8 & 9 & 1 & 4 & 0 & 14 & 205,8 & 190,0 & 43,7 & 44,4 & 14,6 & 32,6 \\
\hline 9 & 4 & 2 & 6 & 2 & 14 & 65,8 & 127,1 & 44,2 & 60,8 & 6,8 & 29,4 \\
\hline 10 & 10 & 1 & 7 & 0 & 18 & 213,2 & 192,7 & 57,9 & 38,6 & 8,4 & 21,1 \\
\hline 11 & 9 & 1 & 5 & 0 & 15 & 155,8 & 186,2 & 51,0 & 46,8 & 18,6 & 50,2 \\
\hline 12 & 6 & 3 & 4 & 0 & 12 & 278,2 & 328,8 & 68,4 & 152,0 & 26,3 & 99,9 \\
\hline$\Sigma$ & 69 & 16 & 41 & 11 & 137 & 1783,4 & 1804,9 & & & 14,2 & \\
\hline \multicolumn{12}{|c|}{ Normal } \\
\hline 1 & 3 & 1 & 9 & 0 & 13 & 46,3 & 77,9 & 26,8 & 9,4 & 8,7 & 56,2 \\
\hline 2 & 7 & 3 & 7 & 0 & 17 & 227,4 & 297,6 & 60,5 & 120,6 & 12,8 & 78,0 \\
\hline 3 & 1 & 5 & 5 & 0 & 11 & 69,5 & 62,3 & 57,4 & 56,6 & 11,6 & 57,4 \\
\hline 7 & 2 & 1 & 1 & 0 & 4 & 23,7 & 20,2 & 13,7 & 12,0 & 6,0 & 13,7 \\
\hline 8 & 5 & 1 & 3 & 0 & 9 & 129,5 & 113,2 & 51,0 & 39,8 & 15,0 & 51,0 \\
\hline 9 & 11 & 3 & 3 & 1 & 18 & 80,5 & 65,3 & 15,8 & 17,6 & 3,7 & 9,2 \\
\hline 10 & 6 & 3 & 6 & 1 & 16 & 157,9 & 124,8 & 58,4 & 26,0 & 14,4 & 51,0 \\
\hline 11 & 3 & 1 & 6 & 0 & 10 & 22,6 & 24,2 & 10,0 & 7,8 & 3,6 & 9,2 \\
\hline 12 & 3 & 4 & 9 & 0 & 16 & 115,8 & 116,4 & 40,0 & 36,0 & 13,5 & 40,0 \\
\hline$\Sigma$ & 41 & 22 & 49 & 2 & 114 & 873,2 & 901,9 & & & 9,9 & \\
\hline
\end{tabular}

OBS: As precipitações foram registradas da seguinte forma: 1) nas duas estações, CP e Agr no mesmo dia, é $C+A$; 2) somente em uma estação, $C P$ ou $A g r ; 3)$ na estação Agr, quando na estação CP não tinha dados, é $A / S d$, 4) em uma das estações ou nas duas juntamente, é $\sum$. Quantidade de

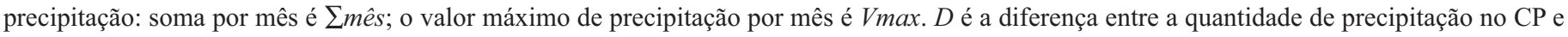
na Agr: Dmed é o valor médio de D; Dmax é o valor máximo de $D$ por mês. Na coluna $\mathrm{D}_{\text {med }}$ o valor na linha $\Sigma$ é uma média. 
Tabela 2 - Número de casos de situações sinóticas associadas com precipitação em Pelotas (na estação CPMET ou Agr), para os meses dos anos de La Niña, El Niño e Normal estudados.

As frentes são representadas como segue: Fria; $\boldsymbol{Q}$ é quente; $\boldsymbol{O} \boldsymbol{c}$ é oclusa; $\boldsymbol{S e c}$ é secundária; Poc é próximo do ponto de oclusão.

\begin{tabular}{|c|c|c|c|c|c|c|c|c|c|c|c|c|c|c|c|c|c|c|c|}
\hline \multirow{3}{*}{ Mês } & \multicolumn{11}{|c|}{ Frentes } & \multicolumn{3}{|c|}{ Ciclone } & \multicolumn{4}{|c|}{ MA } & \multirow{3}{*}{ Rar } \\
\hline & \multicolumn{6}{|c|}{ Fria } & \multirow{2}{*}{$Q$} & \multirow{2}{*}{$O c$} & \multirow{2}{*}{$S e c$} & \multirow{2}{*}{ Poc } & \multirow{2}{*}{$\Sigma$} & \multirow{2}{*}{$C c$} & \multirow{2}{*}{$C g$} & \multirow{2}{*}{$\Sigma$} & \multirow{2}{*}{$C C M$} & \multirow{2}{*}{$S t$} & \multirow{2}{*}{$C b$} & \multirow{2}{*}{$\Sigma$} & \\
\hline & van & cen & ret & ext & ond & ina & & & & & & & & & & & & & \\
\hline \multicolumn{20}{|c|}{ La Niña } \\
\hline 1 & 2 & 4 & & & 1 & 3 & & 2 & & 1 & 13 & 2 & & 2 & & 2 & 2 & 4 & \\
\hline 2 & & 1 & 2 & & 2 & & & 1 & & & 6 & & & & & & 1 & 1 & \\
\hline 3 & 2 & 1 & 3 & 3 & 3 & & & & & & 12 & & & & & 3 & 1 & 4 & \\
\hline 7 & & 5 & & 2 & & & 1 & & & & 8 & & 2 & 2 & & 2 & & 2 & \\
\hline 8 & & 2 & & 3 & 1 & & & 1 & & 2 & 9 & 1 & 1 & 2 & & 3 & & 3 & \\
\hline 9 & & 9 & 1 & & & & & 1 & & 2 & 13 & & 2 & 2 & & 2 & & 2 & \\
\hline 10 & & 3 & & & & & & 1 & & 1 & 5 & & & & & 2 & 1 & 3 & \\
\hline 11 & & 2 & 1 & & 2 & & 1 & 1 & 2 & & 9 & 1 & & 1 & & 1 & 1 & 2 & \\
\hline 12 & & 4 & 2 & & 1 & & & 5 & & 3 & 15 & 1 & 2 & 3 & & 3 & 1 & 4 & \\
\hline$\sum$ & 4 & 31 & 9 & 8 & 10 & 3 & 2 & 12 & 2 & 9 & 90 & 5 & 7 & 12 & & 18 & 7 & 25 & \\
\hline \multicolumn{20}{|c|}{ El Niño } \\
\hline 1 & & 6 & 3 & 5 & 4 & & & & & & 18 & & & & 1 & 2 & & 3 & \\
\hline 2 & 1 & 3 & 1 & & 2 & 1 & & 1 & & & 9 & & 3 & 3 & & 3 & 1 & 4 & \\
\hline 3 & & 2 & & & 3 & 2 & 2 & 5 & & 1 & 15 & & 2 & 2 & & 4 & & 4 & \\
\hline 7 & & 2 & & & 2 & & & & & & 4 & & 2 & 2 & & 3 & & 3 & $R$ \\
\hline 8 & 1 & 5 & 2 & & 4 & & & 1 & & & 13 & & & & & 1 & & 1 & \\
\hline 9 & 2 & 5 & 1 & 2 & 1 & & 2 & & & & 13 & & 3 & 3 & & 3 & & 3 & \\
\hline 10 & & 6 & 2 & 2 & 3 & 1 & 3 & & & 3 & 20 & & 1 & 1 & 1 & 2 & 1 & 4 & \\
\hline 11 & 1 & 7 & 1 & & 3 & & 2 & & & 1 & 15 & & 1 & 1 & & 2 & & 2 & $s q$ \\
\hline 12 & & 7 & 3 & 1 & 1 & & 4 & & & 3 & 19 & & 1 & 1 & & & 1 & 1 & \\
\hline$\sum$ & 5 & 43 & 13 & 10 & 23 & 4 & 13 & 7 & & 8 & 126 & & 13 & 13 & 2 & 20 & 3 & 25 & 2 \\
\hline \multicolumn{20}{|c|}{ Normal } \\
\hline 1 & 1 & 4 & & 1 & 1 & & & & & & 7 & & & & & 5 & 1 & 6 & \\
\hline 2 & 1 & 5 & & 1 & & 2 & & 1 & & & 10 & & 1 & 1 & 2 & 4 & 1 & 7 & \\
\hline 3 & 1 & 1 & & & 1 & & 1 & & & & 4 & 1 & 1 & 2 & & 3 & 3 & 6 & \\
\hline 7 & & 1 & & & & & & 3 & & 1 & 5 & & & & & 1 & & 1 & \\
\hline 8 & 1 & 2 & 2 & 1 & 2 & & 1 & & & & 9 & & & & 1 & & & 1 & \\
\hline 9 & & 1 & & 3 & 2 & 1 & 1 & 3 & 3 & & 14 & 1 & & 1 & & 1 & 3 & 4 & \\
\hline 10 & & 4 & 1 & & 2 & & & 3 & & & 10 & & 2 & 2 & & 2 & 2 & 4 & \\
\hline 11 & 1 & 2 & 1 & & 2 & 2 & & 1 & & & 9 & & & & & 1 & & 1 & \\
\hline 12 & 2 & 2 & 2 & 1 & 4 & & & & & & 11 & & & & & 2 & 3 & 5 & \\
\hline$\sum$ & 7 & 22 & 6 & 7 & 14 & 5 & 3 & 11 & 3 & 1 & 79 & 2 & 4 & 6 & 3 & 19 & 13 & 35 & \\
\hline
\end{tabular}

OBS: Partes da frente fria: van é a vanguarda, cen é a parte central, ret é a retaguarda, ext é a extremidade da frente, ond é uma onda ativa na frente, ina é frente inativa e fraca.

Ciclones: $\boldsymbol{C} \boldsymbol{c}$ é o centro do ciclone nos estágios de onda e de ciclone jovem; $\boldsymbol{C} \boldsymbol{g}$ é uma massa de nuvens ciclogenética.

MA são as nuvens dentro de uma massa de ar: $\boldsymbol{C C M}$ é complexo convectivo de mesoescala, $\boldsymbol{S} \boldsymbol{t}$ são nuvens estratiformes de baixos níveis, $\boldsymbol{C b}$ são nuvens convectivas.

Rar são situações sinóticas raras: $s q$ é setor quente; $R$ é a regeneração da frente sobre o sul do Uruguai devido à união com uma massa de nuvens com curvatura anticiclônica. 
Foram identificadas as seguintes frentes: fria (fria), quente $(\boldsymbol{Q})$, oclusa $(\boldsymbol{O} \boldsymbol{c})$ e secundária $(\boldsymbol{S e c})$. Também foram determinadas as precipitações próximo ao ponto de oclusão $(\boldsymbol{P o c})$, ou seja, entre as frentes quente e fria. Para as frentes frias foram identificadas as diferentes partes da mesma, ou seja, vanguarda (van), retaguarda (ret ) e extremidade (ext) da frente. Isto significa que durante todo o dia as precipitações foram associadas com uma parte da frente. Por exemplo, durante o dia a frente fria se localizou sobre o Uruguai e as precipitações em Pelotas foram associadas à vanguarda desta frente. Os casos em que durante um dia foi observada a passagem de uma frente fria e não predominou somente uma parte dela (van, ret ou ext), foram anotados como passagem da frente fria ou parte central (cen) da frente. Foram marcadas as passagens de frentes frias com ondas ativas (ond) e frentes inativas e fracas (ina). $\mathrm{Na}$ imagem do canal infravermelho, uma onda ativa na frente é determinada pelo aumento da largura da frente e pela cor muito clara nesta região (Andersen, 1973; Fedorova e Bakst, 1996). As frentes fracas caracterizam-se pela cor cinza da banda de nebulosidade.

As situações sinóticas em que as precipitações estavam associadas com uma massa de nuvens ciclogenética (Fedorova et al. 1999, Fedorova e Bakst, 1999b) foram mencionadas como ciclogênese $(\boldsymbol{C g})$. As precipitações próximas ao centro do ciclone nos estágios de onda e de ciclone jovem, ou seja, até a formação da frente oclusa, foram chamadas de centro de baixa $(\boldsymbol{C c})$. Estas duas situações foram mencionadas condicionalmente como ciclones.

As precipitações dentro de uma massa de ar estavam associadas com complexo convectivo de mesoescala, $\boldsymbol{C C M}$ (Maddox, 1983; Fedorova e Khan, 1999) e, também, com nuvens estratiformes de baixos níveis $(\boldsymbol{S} \boldsymbol{t})$ e com nuvens convectivas $(\boldsymbol{C b})$.

As situações sinóticas raras ( Rar ) associadas com precipitações foram: 1) setor quente do ciclone (sq) e 2) regeneração (R) de frentes sobre o sul do Uruguai devido à união com uma massa de nuvens com curvatura anticiclônica (Fedorova et al., 2000; Fedorova e Bakst, 1999a).

Foram determinadas as situações sinóticas ligadas aos Períodos $\geq 3$ dias com precipitação. Foi denominado Período associado com frente $(\boldsymbol{F r})$, se durante a seqüência de dias foi identificada uma zona frontal associada às precipitações. Este processo também se chama frente estacionária. Nos outros casos, o Periodo $\geq 3$ foi associado com o processo de ciclogênese e, posteriormente, com frentes (fria e/ou quente e/ou oclusa); este processo completo foi denominado, de forma abreviada como $(\boldsymbol{C g} \rightarrow \boldsymbol{F r})$. Foram determinadas as quantidades de dias destes Períodos.

\subsection{Definição das precipitações muito intensas, intensas, médias e fracas}

As precipitações foram divididas em quatro grupos: fracas (0-5 mm/24h nas duas estações), médias (6-20 mm/24h nas duas estações ou somente em uma e, na outra, fracas), intensas (21-40 mm/24h nas duas estações ou somente em uma e, na outra, fracas ou médias) e muito intensas (em uma das estações $\geq 41 \mathrm{~mm} / 24 \mathrm{~h}$ ). Foi feita uma análise da freqüência dos sistemas e processos sinóticos, mencionados na Seção 2.2, associados a precipitações de diferentes intensidades, ou seja, muito intensas, intensas, médias e fracas.

\subsection{Análise da variação da precipitação durante os meses de estudo nos anos de La Niña, de El Niño e Normal}

Para cada um dos sistemas e situações sinóticas, foi calculado o valor total mensal da precipitação (precipitação total mensal, PTM). A PTM mostra o valor das precipitações geradas por cada sistema sinótico durante um mês. Além disso, para cada um dos sistemas e situações sinóticas foi calculado o valor médio da precipitação observada durante os vários eventos ocorridos dentro de cada mês, que será chamado daqui por diante de precipitação média (PM). Assim, a PM mostra o valor da precipitação média (durante um mês) ocasionada por cada tipo de sistema sinótico. Foi feita uma análise das variações mensais destes dois valores durante nove meses de um ano em que ocorreu La Niña, de um ano de El Niño e de um ano normal.

\section{RESULTADOS}

\subsection{Características das precipitações e dos sistemas e processos}

\subsubsection{Características das precipitações nas estações CPMET e Agr}

As características das precipitações nas estações CPMET e Agr no período de estudo são apresentadas na Tabela 1. Os dados desta Tabela mostram que a quantidade de dias com precipitações nas duas estações foi de 69 no ano de El Nino, 44 no ano de La Niña e 41 no ano Normal. A quantidade de dias em que as precipitações foram observadas em uma das estações ou nas duas foi máxima (137 dias) no ano de El Niño e mínima no ano de La Niña (105 dias). Esta quantidade de dias por mês foi máxima em janeiro do ano de El Niño (20 dias) e atingiu 18 dias nos meses de março e outubro do mesmo ano. Esta quantidade de dias foi menor no ano de La Niña (16 dias nos meses de março e dezembro). 
As quantidades de precipitação nas estações CPMET e Agr foram quase iguais para todos os meses e anos (Tabela 1). A quantidade de precipitação durante nove meses foi, aproximadamente, duas vezes maior no ano de El Niño do que nos anos de La Niña e Normal. A quantidade máxima de precipitação acumulada durante nove meses do período estudado atingiu 1805 e 1783 mm. nas estações Agr e CPMET, respectivamente, e foi observada no ano de El Niño. A diferença entre a quantidade de precipitação no CPMET e na Agr ficou, em média, entre 9 e $14 \mathrm{~mm} / 24 \mathrm{~h}$ e atingiu o valor máximo $99,9 \mathrm{~mm} / 24 \mathrm{~h} \mathrm{em}$ um caso, em dezembro do ano de El Niño.

\subsubsection{Situações sinóticas associadas às precipitações em Pelotas}

As precipitações em Pelotas estiveram associadas a zonas frontais com uma maior freqüência no ano de El Niño

a)

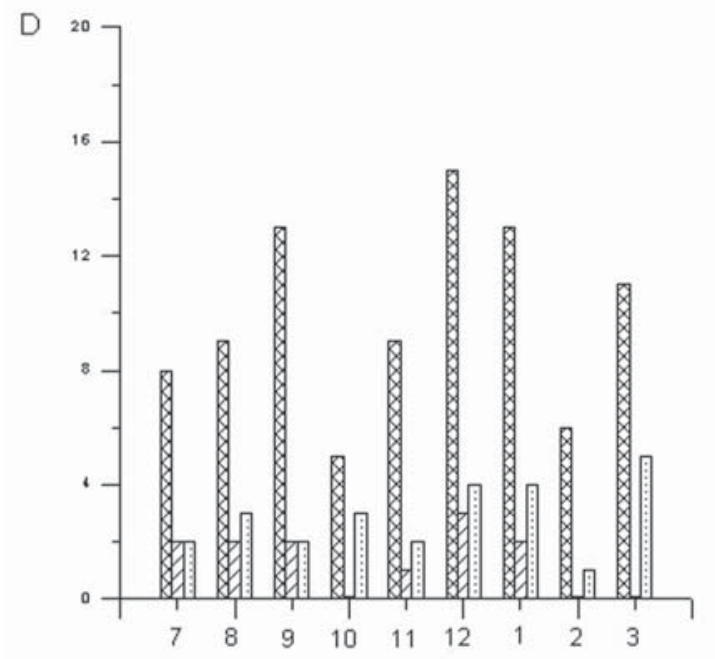

(126 casos, Tabela 2 e Figura 1) do que nos anos de La Niña (90 casos) e Normal (79 casos). As precipitações associadas a passagens de frentes frias, a ondas nas frentes frias e a frentes quentes foram, também, mais freqüentes no ano de El Niño (43, 23 e 13 casos, respectivamente) do que no ano de La Niña (31, 10 e 2 casos, respectivamente). As precipitações nas frentes oclusas e secundárias foram mais freqüentes no ano de La Niña, comparando com o ano de El Niño; todavia, comparando-se com o ano Normal a quantidade destas frentes foi quase a mesma.

As quantidades de dias com precipitações associadas com o processo de ciclogênese e o centro do ciclone jovem foram quase iguais nos anos de El Niño e de La Niña e muito menores no ano Normal. Por outro lado, os casos de precipitação numa massa de nuvens ciclogenética foram mais numerosos no ano de El Niño (13 casos) do que no ano de La Niña (somente 7 casos).

b)

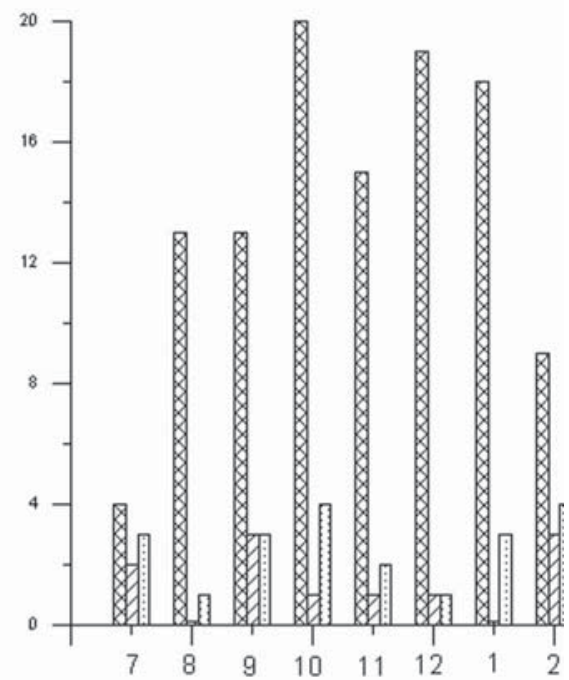

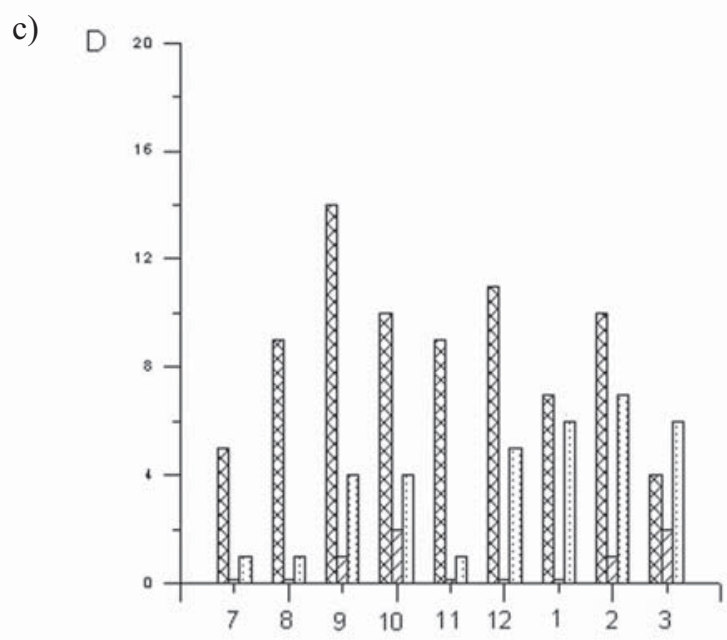

Figura 1 - Quantidade de dias com precipitação (eixo Y) associados com frentes (colunas com linhas cruzadas), ciclones (colunas com linhas inclinadas) e uma massa de ar (colunas com pontos) para os nove meses dos anos de La Niña (a), de El Niño (b) e Normal (c). No eixo X, os meses são números: 7, 8... 12...3. 
As precipitações dentro uma massa de ar foram mais freqüentes no ano Normal (35 casos) e mais raras nos anos de El Niño e de La Niña (25 casos em cada um destes anos). O desenvolvimento de nuvens convectivas predominou nos anos Normal (13 casos) e de La Niña (7 casos); já no ano de El Niño foram observados somente 3 casos. Foram registrados dois CCM's no ano de El Niño e três no ano Normal.

A Figura 2 mostra a variação, durante nove meses dos anos de El Niño, de La Niña e Normal, da quantidade de dias com precipitações associadas com frentes, ciclones e uma massa de ar. No ano Normal a quantidade máxima de dias com precipitação associada com frentes foi registrada no fim do inverno (em setembro). Nos anos de El Niño e de La Niña esta quantidade máxima foi observada. na primavera e verão (outubro e dezembro, respectivamente). Nos meses de outubro,

a)

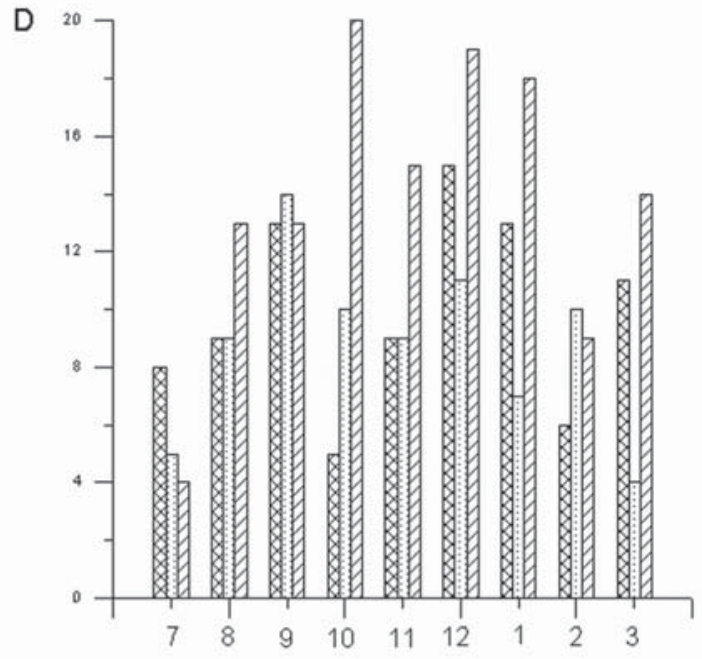

novembro, dezembro e janeiro do ano de El Niño, período em que foi observada a fase ativa do fenômeno, a quantidade de dias com precipitações associadas a frentes foi muito maior do que no ano Normal.

O fenômeno La Niña do ano de 1998 não foi muito intenso, mas atingiu os valores máximos de anomalias negativas de TSM nos meses de dezembro e janeiro, quando foi registrado um maior número de dias com precipitações associadas a frentes (15 e 13, respectivamente). Nos meses de outubro e novembro ocorreu a intensificação do fenômeno La Niña e a quantidade de dias com precipitações associadas às frentes aumentou de 5 para 9 . Em geral, no período de outubro até janeiro a quantidade de dias com precipitações associadas a frentes foi maior no ano de La Niña do que no ano Normal.

b)

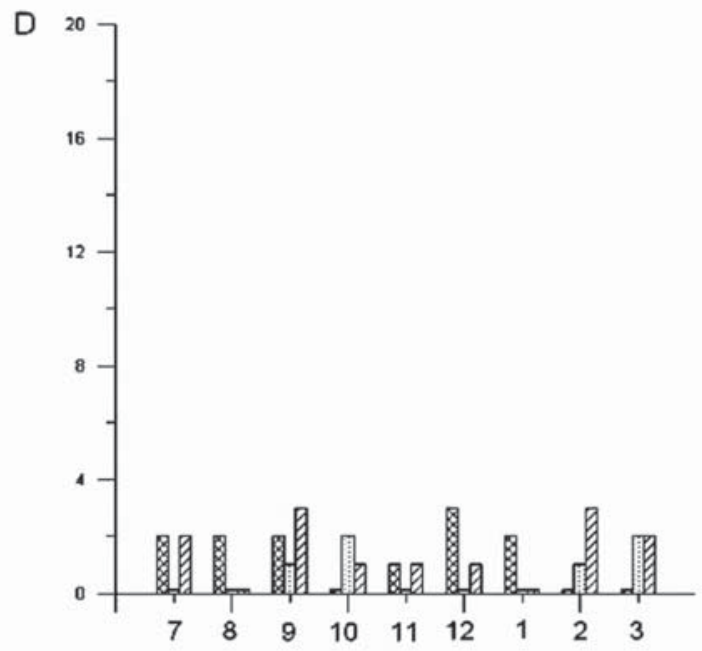

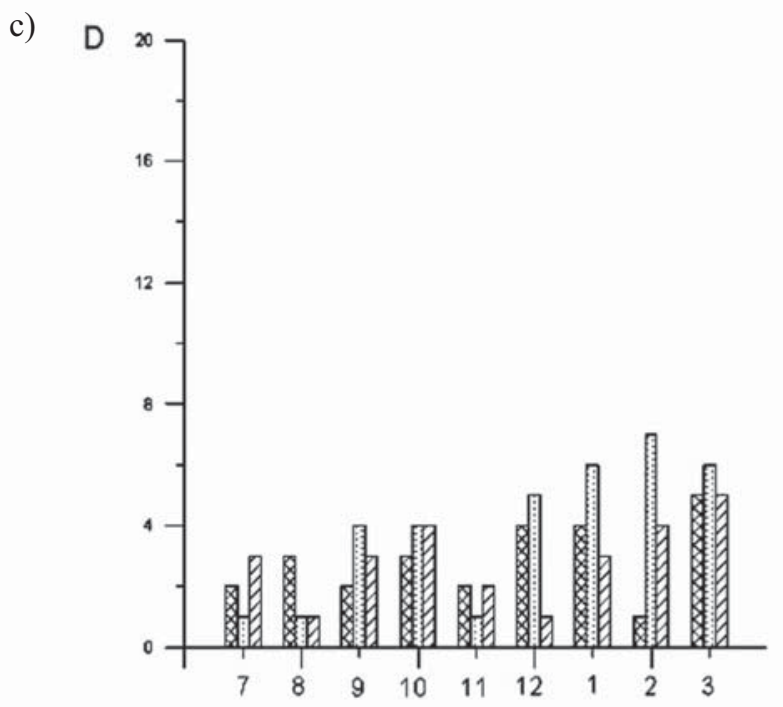

Figura 2 - Quantidade de dias com precipitação (eixo Y) associada a frentes (a), ciclones (b) e uma massa de ar (c) para os nove meses dos anos de La Niña (colunas com linhas cruzadas), de El Niño (colunas com linhas inclinadas) e Normal (colunas com pontos). No eixo $\mathrm{X}$, os meses são números: $7,8 \ldots 12 \ldots 3$. 
Os dados da Tabela 3 mostram que durante todos os anos analisados existiram dias em que as precipitações durante 24 horas foram associadas com dois e três processos sinóticos. Por exemplo, de manhã uma frente fria deslocou-se da região de Pelotas e à noite entrou uma nova frente fria nesta região. Os casos em que as precipitações durante 24 horas foram associadas com dois ou três processos sinóticos foram observados em 17 e $15 \%$ dos dias com precipitações nos anos de La Niña e de El Niño, respectivamente. No ano Normal estes casos foram menos numerosos; somente $5 \%$ dos dias com precipitações.

Tabela 3 - Quantidade (Q) de dias com 1, 2 ou 3 processos sinóticos, associados com precipitação durante 24 horas. $\mathbf{N}$ é a quantidade de processos sinóticos identificados por mês.

\begin{tabular}{|c|c|c|c|c|}
\hline \multirow{2}{*}{ mês } & \multicolumn{3}{|c|}{$\mathbf{Q}$} & \multirow{2}{*}{$\mathbf{N}$} \\
\hline & 1 & 2 & 3 & \\
\hline \multicolumn{5}{|c|}{ La Niña } \\
\hline 1 & 8 & 4 & 1 & 19 \\
\hline 2 & 7 & & & 7 \\
\hline 3 & 16 & & & 16 \\
\hline 7 & 8 & 2 & & 12 \\
\hline 8 & 10 & 2 & & 14 \\
\hline 9 & 12 & 1 & 1 & 17 \\
\hline 10 & 5 & & 1 & 8 \\
\hline 11 & 10 & 1 & & 12 \\
\hline 12 & 11 & 4 & 1 & 22 \\
\hline$\Sigma$ & 87 & 14 & 4 & 127 \\
\hline \multicolumn{5}{|c|}{ El Niño } \\
\hline 1 & 19 & 1 & & 21 \\
\hline 2 & 14 & 1 & & 16 \\
\hline 3 & 15 & 3 & & 21 \\
\hline 7 & 10 & & & 10 \\
\hline 8 & 14 & & & 14 \\
\hline 9 & 10 & 3 & 1 & 19 \\
\hline 10 & 14 & 1 & 3 & 25 \\
\hline 11 & 12 & 2 & 1 & 19 \\
\hline 12 & 8 & 2 & 3 & 21 \\
\hline$\sum$ & 116 & 13 & 8 & 166 \\
\hline \multicolumn{5}{|c|}{ Normal } \\
\hline 1 & 13 & & & 13 \\
\hline 2 & 16 & 1 & & 18 \\
\hline 3 & 10 & 1 & & 12 \\
\hline 7 & 3 & & 1 & 6 \\
\hline 8 & 8 & 1 & & 10 \\
\hline 9 & 17 & 1 & & 19 \\
\hline 10 & 16 & & & 16 \\
\hline 11 & 10 & & & 10 \\
\hline 12 & 16 & & & 16 \\
\hline$\sum$ & 109 & 4 & 1 & 120 \\
\hline
\end{tabular}

\subsubsection{Duração das precipitações nas estações CPMET e Agr e situações sinóticas associadas aos Períodos maiores do que 3 dias}

As precipitações que duraram um ou dois dias foram observadas um pouco mais freqüentemente no ano de La Niña do que no ano de El Niño (Tabela 4). Os Períodos $\geq 3$ dias foram mais freqüentes no ano de El Niño e atingiram 7 dias em fevereiro. Neste ano foram observados três Períodos em que as precipitações começaram no fim de um mês e continuaram nos primeiros dias do mês seguinte. Um destes Períodos durou 13 dias.

Os dados da Tabela 4 também mostram que em geral, no ano de El Niño foram registrados os processos $\boldsymbol{F r}$ e $\boldsymbol{C g} \rightarrow \boldsymbol{F r}$ com duração de 3, 4 e 5 dias com freqüência duas vezes maior do que no ano de La Niña (16 e 8 Períodos para estes anos respectivamente). Um maior número de Períodos com precipitação em dias consecutivos ( $\geq 3$ dias) e associados com processos $\boldsymbol{F r}$, foi registrado no ano de El Niño comparando-se com o ano de La Niña (11 e 2 Períodos para estes anos respectivamente). Os processos $\boldsymbol{C} \boldsymbol{g} \rightarrow \boldsymbol{F r}$ de mesma duração tiveram quase a mesma freqüência nos anos de La Niña e de El Niño (6 e 5 Períodos para estes anos, respectivamente).

\subsection{Precipitações muito intensas, intensas, médias e fracas}

\subsubsection{Situações sinóticas associadas às precipitações muito intensas em Pelotas}

A quantidade de dias com precipitações muito intensas (Tabela 5) nos anos de La Niña e Normal foi 7 e 8, respectivamente; todavia, no ano de El Niño esta quantidade foi muito maior, ou seja, 21 dias. As quantidades de situações sinóticas associadas a estas precipitações foram 30, 10 e 9 nos anos de El Niño, de La Niña e Normal, respectivamente.

As precipitações muito intensas estiveram associadas principalmente às zonas frontais em todos os anos analisados. Foram registradas 28 zonas frontais que geraram precipitações muito intensas no ano de El Niño e muito menos (9 e 5 zonas frontais, respectivamente) nos anos de La Niña e Normal. Precipitações muito intensas foram observadas mais freqüentemente durante passagens de frentes frias (11 no ano de El Niño). Além disso, frentes oclusas, ondas em frentes frias (máximo de 6 casos no ano de El Niño) e extremidades de frentes frias foram associadas a precipitações muito intensas durante todos os anos. Também foram registrados quatro casos com estas precipitações próximas do ponto de oclusão e três casos relacionados com frentes quentes no ano de El Niño.

Precipitações muito intensas também foram observadas em ciclones jovens, ou seja, estas precipitações estavam associadas ao processo de ciclogênese (um caso em cada um dos anos 
Tabela 4 - Quantidade de casos em que as precipitações foram registradas num período de 1 a 9 dias consecutivos em uma ou nas duas estações, CPMET e/ou Agr (QC) e quantidade de processos $(\boldsymbol{Q P}), \boldsymbol{F r}$ e $\boldsymbol{C g} \rightarrow \boldsymbol{F r}$, associados com as seqüências de dias (3, 4 e 5 dias) com precipitação para os meses dos anos de La Nina, El Niño e Normal

\begin{tabular}{|c|c|c|c|c|c|c|c|c|c|c|c|c|c|c|c|c|c|}
\hline \multirow{3}{*}{ mês } & \multicolumn{10}{|c|}{$Q D$} & \multicolumn{7}{|c|}{$Q P$} \\
\hline & \multirow{2}{*}{1} & \multirow{2}{*}{2} & \multirow{2}{*}{3} & \multirow{2}{*}{4} & \multirow{2}{*}{5} & \multirow{2}{*}{6} & \multirow{2}{*}{7} & \multirow{2}{*}{8} & \multirow{2}{*}{9} & \multirow{2}{*}{$\Sigma$} & \multicolumn{3}{|c|}{$F r$} & \multicolumn{3}{|c|}{$C g \rightarrow F r$} & \multirow{2}{*}{$\Sigma$} \\
\hline & & & & & & & & & & & 3 & 4 & 5 & 3 & 4 & 5 & \\
\hline \multicolumn{18}{|c|}{ La Niña } \\
\hline 1 & 3 & & 2 & 1 & & & & & & 6 & & & & & & & \\
\hline 2 & 3 & 2 & & & & & & & & 5 & & & & & & & \\
\hline 3 & & 2 & 1 & 1 & 1 & & & & & 5 & 1 & & 1 & & & & 2 \\
\hline 7 & 1 & 3 & 1 & & & & & & & 5 & & & & 1 & & & 1 \\
\hline 8 & 3 & 2 & & & 1 & & & & & 6 & & & & & & 1 & 1 \\
\hline 9 & & 4 & & & & 1 & & & & 5 & & & & & 1 & & 1 \\
\hline 10 & 2 & 2 & & & & & & & & 4 & & & & & & & \\
\hline 11 & 1 & 3 & & 1 & & & & & & 5 & & & & & 1 & & 1 \\
\hline 12 & 2 & 2 & 2 & 1 & & & & & & 7 & & & & 2 & & & 2 \\
\hline$\Sigma$ & 15 & 20 & 6 & 4 & 2 & 1 & & & & 48 & 1 & & 1 & 3 & 2 & 1 & 8 \\
\hline \multicolumn{18}{|c|}{ El Niño } \\
\hline 1 & 2 & & 2 & 1 & & 1 & & & & 6 & 3 & 1 & & & & & 4 \\
\hline 2 & 2 & 1 & & 1 & & & 1 & & & 5 & & & & & & & \\
\hline 3 & 1 & & & 3 & 1 & & & & & 5 & 1 & & 1 & 1 & & & 3 \\
\hline 7 & 1 & 2 & & & 1 & & & & & 4 & & & & 1 & & & 1 \\
\hline 8 & & 2 & 2 & 1 & & & & & & 5 & 1 & 1 & & & & & 2 \\
\hline 9 & 2 & 2 & 1 & & 1 & & & & & 6 & 1 & & & & & 1 & 2 \\
\hline 10 & 2 & 5 & 1 & & & & & & & 8 & 2 & & & & & & 2 \\
\hline 11 & 1 & 4 & & & & 1 & & & & 6 & & & & 1 & & & 1 \\
\hline 12 & 3 & 1 & 1 & 1 & & & & & & 6 & & & & & 1 & & 1 \\
\hline$\Sigma$ & 14 & 17 & 7 & 7 & 3 & 2 & 1 & & & 51 & 8 & 2 & 1 & 3 & 1 & 1 & 16 \\
\hline \multicolumn{18}{|c|}{ Normal } \\
\hline 1 & 2 & 1 & 3 & & & & & & & 6 & & & & & & & \\
\hline 2 & 2 & 1 & & 1 & & & & & 1 & 5 & & 1 & & & & & 1 \\
\hline 3 & 1 & 1 & & 2 & & & & & & 4 & 1 & & & & & & 1 \\
\hline 7 & & & & 1 & & & & & & 1 & 1 & & & & & & 1 \\
\hline 8 & 2 & 2 & 1 & & & & & & & 5 & 1 & & & & & & 1 \\
\hline 9 & & 1 & 1 & 2 & 1 & & & & & 5 & & 1 & 1 & & & & 2 \\
\hline 10 & 1 & & 2 & & 1 & & & & & 4 & 1 & & & & 4 & & 5 \\
\hline 11 & 2 & 2 & & 1 & & & & & & 5 & & 1 & & & & & 1 \\
\hline 12 & 4 & 1 & & 4 & 1 & & & & & 10 & 1 & & & & & & 1 \\
\hline$\Sigma$ & 14 & 9 & 7 & 11 & 3 & & & & 1 & 45 & 5 & 3 & 1 & & 4 & & 13 \\
\hline
\end{tabular}


Tabela 5 - Quantidade de casos de cada uma das situações sinóticas associadas com precipitações muito intensas (mais do que $41 \mathrm{~mm} / 24$ horas) em Pelotas (na estação CPMET ou Agr) para os meses dos anos de La Niña, El Niño e Normal. Casos é a quantidade de casos de situações sinóticas. Dias é a quantidade de dias com precipitações muito intensas.

\begin{tabular}{|c|c|c|c|c|c|c|c|c|c|c|c|c|c|c|c|c|c|c|c|c|c|}
\hline \multirow{3}{*}{ mês } & \multicolumn{11}{|c|}{ Frentes } & \multicolumn{3}{|c|}{ Ciclone } & \multicolumn{4}{|c|}{ MA } & \multirow{3}{*}{ Rar } & \multirow{3}{*}{ Casos } & \multirow{3}{*}{ Dias } \\
\hline & \multicolumn{6}{|c|}{ Fria } & \multirow{2}{*}{$Q$} & \multirow{2}{*}{$O c$} & \multirow{2}{*}{ Sec } & \multirow{2}{*}{ Poc } & \multirow{2}{*}{$\Sigma$} & \multirow{2}{*}{$C c$} & \multirow{2}{*}{$C g$} & \multirow{2}{*}{$\Sigma$} & \multirow{2}{*}{$C C M$} & \multirow{2}{*}{$S t$} & \multirow{2}{*}{$C b$} & \multirow{2}{*}{$\Sigma$} & & & \\
\hline & van & cen & ret & ext & ond & ina & & & & & & & & & & & & & & & \\
\hline & & & & & & & & & & & $\mathrm{Ni}$ & & & & & & & & & & \\
\hline 1 & & 2 & & & & & & 2 & & 1 & 5 & & & & & & & & & 5 & 2 \\
\hline 2 & & & & & & & & & & & & & & & & & & & & & \\
\hline 3 & & & & & & & & & & & & & & & & & & & & & \\
\hline 7 & & 1 & & & & & & & & & 1 & & & & & & & & & 1 & 1 \\
\hline 8 & & & & 1 & 1 & & & & & & 2 & & 1 & 1 & & & & & & 3 & 3 \\
\hline 9 & & & & & & & & & & & & & & & & & & & & & \\
\hline 10 & & & & & & & & & & & & & & & & & & & & & \\
\hline 11 & & & & & & & & & & & & & & & & & & & & & \\
\hline 12 & & & & & & & & 1 & & & 1 & & & . & & & & & & 1 & 1 \\
\hline$\sum$ & & 3 & & 1 & 1 & & & 3 & & 1 & 9 & & 1 & 1 & & & & & & 10 & 7 \\
\hline & & & & & & & & & & & $\mathrm{Nir}$ & & & & & & & & & & \\
\hline 1 & & & & 1 & 2 & & & & & & 3 & & & & & & & & & 3 & 3 \\
\hline 2 & & 1 & & & 1 & & & & & & 2 & & 1 & 1 & & & & & & 3 & 2 \\
\hline 3 & & & & & & & & 2 & & & 2 & & & & & & & & & 2 & 2 \\
\hline 7 & & & & & 1 & & & & & & 1 & & & & & & & & & 1 & 1 \\
\hline 8 & & 1 & & & 2 & & & & & & 3 & & & & & & & & & 3 & 3 \\
\hline 9 & & 1 & & & & & & & & & 1 & & & & & & & & & 1 & 1 \\
\hline 10 & & 1 & & & & & & & & & 1 & & & & & & & & & 1 & 1 \\
\hline 11 & & 4 & & & & & 1 & & & 1 & 6 & & & & & & & & $s q$ & 7 & 4 \\
\hline 12 & & 3 & 1 & & & & 2 & & & 3 & 9 & & & & & & & & & 9 & 4 \\
\hline$\sum$ & & 11 & 1 & 1 & 6 & & 3 & 2 & & 4 & 28 & & 1 & 1 & & & & & 1 & 30 & 21 \\
\hline & & & & & & & & & & & orm & & & & & & & & & & \\
\hline 1 & & 1 & & & & & & & & & 1 & & & & & & & & & 1 & 1 \\
\hline 2 & & 1 & & 1 & & & & & & & 2 & & & & 1 & & & 1 & & 3 & 3 \\
\hline 3 & & & & & & & & & & & & 1 & 1 & 2 & & & 1 & 1 & & 3 & 2 \\
\hline 7 & & & & & & & & & & & & & & & & & & & & & \\
\hline 8 & & & & & 1 & & & & & & 1 & & & & & & & & & 1 & 1 \\
\hline 9 & & & & & & & & & & & & & & & & & & & & & \\
\hline 10 & & & & & & & & 1 & & & 1 & & & & & & & & & 1 & 1 \\
\hline 11 & & & & & & & & & & & & & & & & & & & & & \\
\hline 12 & & & & & & & & & & & & & & & & & & & & & \\
\hline$\sum$ & & 2 & & 1 & 1 & & & 1 & & & 5 & 1 & 1 & 2 & 1 & & 1 & 2 & & 9 & 8 \\
\hline
\end{tabular}

OBS: Frentes são: fria; $\boldsymbol{Q}$ é quente; $\boldsymbol{O c}$ é oclusa; $\boldsymbol{S e c}$ é secundária; $\boldsymbol{P o c}$ é próximo do ponto de oclusão.

Partes da frente fria: van é vanguarda, cen é a parte central, ret é retaguarda, ext é extremidade da frente, ond é onda ativa na frente, ina é frente inativa e fraca.

Ciclones: $\boldsymbol{C} \boldsymbol{c}$ é o centro do ciclone nos estágios de onda e de ciclone jovem; $\boldsymbol{C g}$ é a massa de nuvens ciclogenética.

MA são as nuvens dentro de uma massa de ar: $\boldsymbol{C C M}$ é complexo convectivo de mesoescala, $\boldsymbol{S} \boldsymbol{t}$ são nuvens estratiformes dos baixos níveis, $\boldsymbol{C b}$ são nuvens convectivas.

Rar são situações sinóticas raras: $s q$ é setor quente; $R$ é a regeneração de uma frente sobre o sul do Uruguai devido à união com uma massa de nuvens com curvatura anticiclônica. 
analisados) e ao centro de um ciclone jovem (um caso no ano Normal). Além disso, no ano Normal foi registrado um dia com $\mathrm{CCM}$ e outro com nuvens $\mathrm{Cb}$.

\subsubsection{Situações sinóticas associadas às precipitações intensas em Pelotas}

As precipitações intensas foram associadas às mesmas situações sinóticas que as precipitações muito intensas (Tabela 6). Estas precipitações nas frentes tiveram o maior número de casos no ano de El Niño (32 casos); um número menor ocorreu no ano de La Niña (22 casos) e no ano Normal foram registrados somente 14 casos. Tanto no ano de La Niña quanto no ano de El Niño as precipitações intensas foram observadas nas frentes oclusas com 4 e 3 casos para estes anos, respectivamente. Relacionados a ondas em frentes frias, no ano de El Niño, foram registrados 7 casos de precipitações intensas; no ano de La Niña houve somente um caso. Nestes mesmos anos, estas precipitações ocorreram também na vanguarda das frentes frias e próximo ao ponto de oclusão.

Precipitações intensas também estiveram associadas a um caso de situação sinótica rara, ou seja, a regeneração de uma frente fria sobre o sul do Uruguai devido à união com uma massa de nuvens com curvatura anticiclônica. Estas precipitações foram registradas nesta massa de nuvens. O processo de regeneração de frentes devido à união com uma massa de nuvens com curvatura anticiclônica está descrito em Fedorova et al. (2000) e em Fedorova \& Bakst (1999).

As precipitações dentro de uma massa de ar devido ao desenvolvimento de convecção ( $\mathrm{Cb}$ e $\mathrm{CCM})$ foram observadas no ano Normal (4 casos) e no ano de El Niño (1 caso).

\subsubsection{Situações sinóticas associadas às precipitações médias em Pelotas}

As precipitações de intensidade média (Tabela 7) foram associadas com quase as mesmas situações sinóticas que as precipitações intensas. Nos anos de La Niña e de El Niño a quantidade de casos de precipitações médias em frentes foi aproximadamente a mesma que nos casos com precipitações intensas e com predominância no ano de El Niño (31 casos). Todavia, no ano Normal a quantidade de frentes que geraram precipitações de intensidade média foi duas vezes maior do que aquelas que originaram precipitações intensas, ou seja, 28 casos contra 14 . Foram registrados casos de associação de precipitações de intensidade média (até $8 \mathrm{~mm} / 12$ horas e um caso de $15 \mathrm{~mm} / 12$ horas) com nuvens $S t$, predominantemente no ano de La Niña (4 casos).

\subsubsection{Situações sinóticas associadas às precipitações fracas em Pelotas}

Precipitações fracas foram observadas em todos os anos analisados com quase a mesma freqüência, ou seja, a quantidade de dias variou entre 53 no ano de La Niña e 59 no ano Normal (Tabela 8). Comparando-se com os dados das Tabelas 1, 2 e 3 pode-se concluir que em todos os anos as precipitações fracas foram observadas quase em todas as situações sinóticas mencionadas nas tabelas. Além disso, as quantidades destas situações e de dias com precipitações fracas foram maiores que os mesmos (dias e situações) associados às precipitações de maior intensidade (médias, intensas e muito intensas). Por exemplo, a diferença entre a quantidade de dias com precipitações fracas e médias nas frentes é 17 dias para o ano de La Niña e 4 dias para os anos de El Niño e Normal

É muito importante ressaltar que as precipitações relacionadas com a presença de nuvens $S t$ foram, predominantemente, fracas. A quantidade de dias com este tipo de nuvem e precipitação variou pouco, de 14 no ano de La Niña a 19 no ano de El Niño.

\subsubsection{Comparação da freqüência de precipitações associa- das às diferentes situações sinóticas nos anos de La Niña, de El Niño e Normal}

A comparação da freqüência de precipitações associadas aos diferentes tipos de frentes (fria, quente, e oclusa) e também à extremidade da frente fria, a uma onda na frente fria e à região próximo do ponto de oclusão nos anos escolhidos foi feita utilizando-se os dados das Tabelas 5, 6, 7 e 8 (pois estas tabelas foram usadas para todas as conclusões feitas neste item e elas não serão citadas individualmente). As mesmas comparações foram feitas para todas as situações de frentes em conjunto, ciclones, nuvens St e nuvens Cb. Além disso, foram calculados os valores médios das precipitações (VMP), utilizando-se todos os casos de cada situação sinótica, e estão apresentados na Figura 3.

Em geral, a quantidade de casos diminui com o aumento da quantidade de precipitação. Todavia, no ano de El Niño, a quantidade de casos de precipitação associada a passagens de frentes frias (cen) apresentou seu valor máximo para as precipitações intensas (15 casos, Tabela 6) e diminuiu um pouco para as precipitações muito intensas (11 casos, Tabela 5). A mesma conclusão pode ser tirada pelos valores médios (pelo VMP na Figura 3). Para estas duas situações (precipitações intensas e muito intensas), a quantidade de casos com precipitação (QCP) e o VMP foram muito maiores no ano de El Niño do que nos outros anos. Além disso, no mesmo ano pequenas variações de QCP com o aumento da quantidade de precipitação foram 
Tabela 6 - Quantidade de casos de cada uma das situações sinóticas associadas com precipitações intensas (21- 40mm/24 horas) em Pelotas (na estação CPMET ou Agr) para os meses dos anos de La Niña, El Niño e Normal.

\begin{tabular}{|c|c|c|c|c|c|c|c|c|c|c|c|c|c|c|c|c|c|c|c|c|c|}
\hline \multirow{3}{*}{ mês } & \multicolumn{11}{|c|}{ Frentes } & \multicolumn{3}{|c|}{ Ciclone } & \multicolumn{4}{|c|}{ MA } & \multirow{3}{*}{ Rar } & \multirow{3}{*}{ Casos } & \multirow{3}{*}{ Dias } \\
\hline & \multicolumn{6}{|c|}{ Fria } & \multirow{2}{*}{$Q$} & \multirow{2}{*}{$O c$} & \multirow{2}{*}{$\mathrm{Sec}$} & \multirow{2}{*}{ Poc } & \multirow{2}{*}{$\Sigma$} & \multirow{2}{*}{$C c$} & \multirow{2}{*}{$C g$} & \multirow{2}{*}{$\Sigma$} & \multirow{2}{*}{$C C M$} & \multirow{2}{*}{$S t$} & \multirow{2}{*}{$C b$} & \multirow{2}{*}{$\Sigma$} & & & \\
\hline & van & cen & ret & ext & ond & ina & & & & & & & & & & & & & & & \\
\hline & & & & & & & & & & & Niñ & & & & & & & & & & \\
\hline 1 & 2 & 1 & & & & 1 & & & & & 4 & 1 & & 1 & & & & & & 5 & 3 \\
\hline 2 & & 1 & & & & & & & & & 1 & & & & & & & & & 1 & 1 \\
\hline 3 & & & 1 & & 1 & & & & & & 2 & & & & & & & & & 2 & 2 \\
\hline 7 & & 1 & & 2 & & & & & & & 3 & & & & & & & & & 3 & 3 \\
\hline 8 & 1 & & & & & & & 1 & & & 2 & & & & & & & & & 2 & 2 \\
\hline 9 & & 3 & & & & & & & z & 1 & 4 & & & & & & & & & 4 & 3 \\
\hline 10 & & & & & & & & & & & & & & & & & & & & & \\
\hline 11 & & 1 & & & & & & 1 & & & 2 & 1 & & 1 & & & & & & 3 & 2 \\
\hline 12 & & 1 & & & & & & 2 & & 1 & 4 & & & & & & & & & 4 & 2 \\
\hline$\Sigma$ & 3 & 8 & 1 & 2 & 1 & 1 & & 4 & & 2 & 22 & 2 & & 2 & & & & & & 24 & 18 \\
\hline & & & & & & & & & & & $1 \mathrm{Niñ}$ & & & & & & & & & & \\
\hline 1 & & 3 & & & 2 & & & & & & 5 & & & & & & & & & 5 & 5 \\
\hline 2 & 1 & 1 & & & 1 & & & 1 & & & 4 & 1 & 1 & 2 & & & & & & 6 & 5 \\
\hline 3 & & & & & & & 1 & 2 & & 1 & 4 & & 1 & 1 & & & & & & 5 & 3 \\
\hline 7 & & 2 & & & 1 & & & & & & 3 & & & & & & & & $\mathrm{R}$ & 4 & 4 \\
\hline 8 & & 1 & 1 & & 1 & & & & & & 3 & & & & & & & & & 3 & 3 \\
\hline 9 & & 1 & 1 & & & & & & & & 2 & & & & & & & & & 2 & 1 \\
\hline 10 & & 3 & & & 1 & & 1 & & & 1 & 6 & & & & & & & & & 6 & 4 \\
\hline 11 & & 1 & & & 1 & & & & & & 2 & & & & & & & & & 2 & 2 \\
\hline 12 & & 3 & & & & & & & & & 3 & & & & & & 1 & 1 & & 4 & 3 \\
\hline$\Sigma$ & 1 & 15 & 2 & & 7 & & 2 & 3 & & 2 & 32 & 1 & 2 & 3 & & & 1 & 1 & 1 & 37 & 30 \\
\hline & & & & & & & & & & & orm & & & & & & & & & & \\
\hline 1 & & 1 & & & & & & & & & 1 & & & & & & & & & 1 & 1 \\
\hline 2 & & 3 & & & & & & & & & 3 & & 1 & 1 & & & & & & 4 & 3 \\
\hline 3 & & & & & & & & & & & & & & & & & & & & & \\
\hline 7 & & & & & & & & & & & & & & & & & & & & & \\
\hline 8 & & 1 & & 1 & & & 1 & & & & 3 & & & & 1 & & & 1 & & 3 & 2 \\
\hline 9 & & & & & & & & & & & & & & & & & & & & & \\
\hline 10 & & 2 & & & 1 & & & & & & 3 & & 1 & 1 & & & 1 & 1 & & 5 & 5 \\
\hline 11 & & & & & & & & & & & & & & & & & & & & & \\
\hline 12 & & 1 & & & 3 & & & & & & 4 & & & & & & 2 & 2 & & 6 & 6 \\
\hline$\Sigma$ & & 8 & & 1 & 4 & & 1 & & & & 14 & & 2 & 2 & 1 & & 3 & 4 & & 19 & 17 \\
\hline
\end{tabular}

OBS: Frentes são: fria; $\boldsymbol{Q}$ é quente; $\boldsymbol{O} \boldsymbol{c}$ é oclusa; $\boldsymbol{S e c}$ é secundária; $\boldsymbol{P o c}$ é próximo do ponto de oclusão.

Partes da frente fria: van é vanguarda, cen é a parte central, ret é retaguarda, ext é extremidade da frente, ond é onda ativa na frente, ina é frente inativa e fraca.

Ciclones: $\boldsymbol{C} \boldsymbol{c}$ é o centro do ciclone nos estágios de onda e de ciclone jovem; $\boldsymbol{C g}$ é a massa de nuvens ciclogenética.

MA são as nuvens dentro de uma massa de ar: $\boldsymbol{C} \boldsymbol{C M}$ é complexo convectivo de mesoescala, $\boldsymbol{S} \boldsymbol{t}$ são nuvens estratiformes dos baixos níveis, $\boldsymbol{C b}$ são nuvens convectivas.

Rar são situações sinóticas raras: $s q$ é setor quente; $R$ é a regeneração de uma frente sobre o sul do Uruguai devido à união com uma massa de nuvens com curvatura anticiclônica. 
Tabela 7 - Quantidade de casos de cada uma das situações sinóticas associadas com precipitações médias (6 - 20mm/24 horas) em Pelotas (na estação CPMET ou Agr) para os meses dos anos de La Niña, El Niño e Normal.

\begin{tabular}{|c|c|c|c|c|c|c|c|c|c|c|c|c|c|c|c|c|c|c|c|c|c|}
\hline \multirow{3}{*}{ mês } & \multicolumn{11}{|c|}{ Frentes } & \multicolumn{3}{|c|}{ Ciclone } & \multicolumn{4}{|c|}{ MA } & \multirow{3}{*}{ Rar } & \multirow{3}{*}{ Casos } & \multirow{3}{*}{ Dias } \\
\hline & \multicolumn{6}{|c|}{ Fria } & \multirow{2}{*}{$Q$} & \multirow{2}{*}{$O c$} & \multirow{2}{*}{$\mathrm{Sec}$} & \multirow{2}{*}{ Poc } & \multirow{2}{*}{$\Sigma$} & \multirow{2}{*}{$C c$} & \multirow{2}{*}{$\mathrm{Cg}$} & \multirow{2}{*}{$\Sigma$} & \multirow{2}{*}{$C C M$} & \multirow{2}{*}{$S t$} & \multirow{2}{*}{$C b$} & \multirow{2}{*}{$\Sigma$} & & & \\
\hline & van & cen & ret & ext & ond & ina & & & & & & & & & & & & & & & \\
\hline & & & & & & & & & & & $\mathrm{a}$ Niî & & & & & & & & & & \\
\hline 1 & & & & & 1 & & & & & & 1 & & & & & & 1 & 1 & & 2 & 2 \\
\hline 2 & & 1 & & & 1 & & & 1 & & & 3 & & & & & & 1 & 1 & & 4 & 4 \\
\hline 3 & & 1 & & 1 & & & & & & & 2 & & & & & & & & & 2 & 2 \\
\hline 7 & & 3 & & & & & & & & & 3 & & 1 & 1 & & & & & & 4 & 3 \\
\hline 8 & & 1 & & & & & & & & 1 & 2 & & & & & 2 & & 2 & & 4 & 3 \\
\hline 9 & & 5 & & & & & & & & & 5 & & 1 & 1 & & 1 & & 1 & & 7 & 7 \\
\hline 10 & & & & & & & & & & & & & & & & & & & & & \\
\hline 11 & & & 1 & & 1 & & & & & & 2 & & & & & & & & & 2 & 2 \\
\hline 12 & & 1 & & & 1 & & & 1 & & & 3 & & & & & 1 & & 1 & & 4 & 4 \\
\hline$\sum$ & & 12 & 1 & 1 & 4 & & & 2 & & 1 & 21 & & 2 & 2 & & 4 & 2 & 6 & & 29 & 27 \\
\hline & & & & & & & & & & & $1 \mathrm{Niñ}$ & & & & & & & & & & \\
\hline 1 & & 1 & & & & & & & & & 1 & & & & & & & & & 1 & 1 \\
\hline 2 & & 1 & & & & & & & & & 1 & & 1 & 1 & & & & & & 2 & 2 \\
\hline 3 & & & & & 3 & 1 & & 1 & & & 5 & & & & & 1 & & 1 & & 6 & 6 \\
\hline 7 & & & & & & & & & & & & & 1 & 1 & & & & & & 1 & 1 \\
\hline 8 & 1 & 3 & 1 & & 1 & & & & & & 6 & & & & & & & & & 6 & 6 \\
\hline 9 & & & & 2 & 1 & & & & & & 3 & & & & & & & & & 3 & 3 \\
\hline 10 & & 2 & 1 & 2 & 1 & & 2 & & & 2 & 10 & & & & & & & & & 10 & 6 \\
\hline 11 & & 2 & & & 1 & & 1 & & & & 4 & & 1 & 1 & & & & & & 5 & 4 \\
\hline 12 & & & 1 & & & & & & & & 1 & & & & & & & & & 1 & 1 \\
\hline$\sum$ & 1 & 9 & 3 & 4 & 7 & 1 & 3 & 1 & & 2 & 31 & & 3 & 3 & & 1 & & 1 & & 35 & 30 \\
\hline & & & & & & & & & & & ormi & & & & & & & & & & \\
\hline 1 & 1 & 1 & & & & & & & & & 2 & & & & & & & & & 2 & 2 \\
\hline 2 & 1 & 1 & & & & & & & & & 2 & & & & & & & & & 2 & 2 \\
\hline 3 & & & & & & & & & & & & & & & & & & & & & \\
\hline 7 & & 1 & & & & & & 3 & & 1 & 5 & & & & & & & & & 5 & 3 \\
\hline 8 & 1 & 1 & 2 & & & & & & & & 4 & & & & & & & & & 4 & 4 \\
\hline 9 & & 1 & & 2 & 1 & & & 1 & 2 & & 7 & & & & & & 1 & 1 & & 8 & 8 \\
\hline 10 & & 2 & & & & & & 2 & & & 4 & & 1 & 1 & & & & & & 5 & 5 \\
\hline 11 & & & & & 2 & & & & & & 2 & & & & & 1 & & 1 & & 3 & 3 \\
\hline 12 & & 1 & & 1 & & & & & & & 2 & & & & & & & & & 2 & 2 \\
\hline$\sum$ & 3 & 8 & 2 & 3 & 3 & & & 6 & 2 & 1 & 28 & & 1 & 1 & & 1 & 1 & 2 & & 31 & 29 \\
\hline
\end{tabular}

OBS: Frentes são: fria; $\boldsymbol{Q}$ é quente; $\boldsymbol{O} \boldsymbol{c}$ é oclusa; $\boldsymbol{S e c}$ é secundária; $\boldsymbol{P o c}$ é próximo do ponto de oclusão.

Partes da frente fria: van é vanguarda, cen é a parte central, ret é retaguarda, ext é extremidade da frente, ond é onda ativa na frente, ina é frente inativa e fraca.

Ciclones: $\boldsymbol{C} \boldsymbol{c}$ é o centro do ciclone nos estágios de onda e de ciclone jovem; $\boldsymbol{C g}$ é a massa de nuvens ciclogenética.

MA são as nuvens dentro de uma massa de ar: $\boldsymbol{C} \boldsymbol{C M}$ é complexo convectivo de mesoescala, $\boldsymbol{S} \boldsymbol{t}$ são nuvens estratiformes dos baixos níveis, $\boldsymbol{C b}$ são nuvens convectivas.

Rar são situações sinóticas raras: $s q$ é setor quente; $R$ é a regeneração de uma frente sobre o sul do Uruguai devido à união com uma massa de nuvens com curvatura anticiclônica. 
Tabela 8 - Quantidade de casos de cada uma das situações sinóticas associadas com precipitações fracas $(0$ - 5 mm/24 horas) em Pelotas (na estação CP e Agr) para os meses dos anos de La Niña, El Niño e Normal.

\begin{tabular}{|c|c|c|c|c|c|c|c|c|c|c|c|c|c|c|c|c|c|c|c|c|c|}
\hline \multirow{3}{*}{ mês } & \multicolumn{11}{|c|}{ Frentes } & \multicolumn{3}{|c|}{ Ciclone } & \multicolumn{4}{|c|}{ MA } & \multirow{3}{*}{ Rar } & \multirow{3}{*}{ Casos } & \multirow{3}{*}{ Dias } \\
\hline & \multicolumn{6}{|c|}{ Fria } & \multirow{2}{*}{$Q$} & \multirow{2}{*}{$O c$} & \multirow{2}{*}{ Sec } & \multirow{2}{*}{$P o c$} & \multirow{2}{*}{$\Sigma$} & \multirow{2}{*}{$C c$} & \multirow{2}{*}{$C g$} & \multirow{2}{*}{$\Sigma$} & \multirow{2}{*}{$C C M$} & \multirow{2}{*}{$S t$} & \multirow{2}{*}{$C b$} & \multirow{2}{*}{$\Sigma$} & & & \\
\hline & van & cen & ret & ext & ond & ina & & & & & & & & & & & & & & & \\
\hline & & & & & & & & & & & a Niĩ & & & & & & & & & & \\
\hline 1 & & 1 & & & & 2 & & & & & 3 & 1 & & 1 & & 2 & 1 & 3 & & 7 & 6 \\
\hline 2 & & & 2 & & & & & & & & 2 & & & & & & & & & 2 & 2 \\
\hline 3 & 2 & & 2 & 2 & 2 & & & & & & 8 & & & & & 3 & 1 & 4 & & 12 & 12 \\
\hline 7 & & & & & & & 1 & & & & 1 & & 1 & 1 & & 2 & & 2 & & 4 & 3 \\
\hline 8 & & 1 & & 1 & & & & & & 1 & 3 & 1 & & 1 & & 1 & & 1 & & 5 & 4 \\
\hline 9 & & 1 & 1 & & & & & 1 & & 1 & 4 & & 1 & 1 & & 1 & & 1 & & 6 & 4 \\
\hline 10 & & 3 & & & & & & 1 & & 1 & 5 & & & & & 2 & 1 & 3 & & 8 & 6 \\
\hline 11 & & 1 & & & 1 & & 1 & & 2 & & 5 & & & & & 1 & 1 & 2 & & 7 & 7 \\
\hline 12 & & 3 & 1 & & & & & 1 & & 2 & 7 & 1 & 2 & 3 & & 2 & 1 & 3 & & 13 & 9 \\
\hline$\Sigma$ & 2 & 10 & 6 & 3 & 3 & 2 & 2 & 3 & 2 & 5 & 38 & 3 & 4 & 7 & & 14 & 5 & 19 & & 64 & 53 \\
\hline & & & & & & & & & & & $\overline{1 \mathrm{Niñ}}$ & & & & & & & & & & \\
\hline 1 & & 4 & 2 & 3 & & & & & & & 9 & & & & 1 & 2 & & 3 & & 12 & 11 \\
\hline 2 & & 1 & 1 & & & & & & & & 2 & & & & & 3 & 1 & 4 & & 6 & 6 \\
\hline 3 & & 2 & & & & 1 & 1 & & & & 4 & & & & & 3 & & 3 & & 7 & 7 \\
\hline 7 & & & & & & & & & & & & & 1 & 1 & & 3 & & 3 & & 4 & 4 \\
\hline 8 & & & & & & & & 1 & & & 1 & & & & & 1 & & 1 & & 2 & 2 \\
\hline 9 & & 4 & & 1 & & & 2 & & & & 7 & & 3 & 3 & & 3 & & 3 & & 13 & 9 \\
\hline 10 & & & 1 & & 1 & 1 & & & & & 3 & & 1 & 1 & 1 & 2 & 1 & 4 & & 8 & 7 \\
\hline 11 & & 2 & & & 1 & & & & & & 3 & & & & & 2 & & 2 & & 5 & 5 \\
\hline 12 & & 1 & 1 & 1 & 1 & & 2 & & & & 6 & & 1 & 1 & & & & & & 7 & 5 \\
\hline$\sum$ & & 14 & 5 & 5 & 3 & 2 & 5 & 1 & & & 35 & & 6 & 6 & 2 & 19 & 2 & 23 & & 64 & 56 \\
\hline & & & & & & & & & & & orms & & & & & & & & & & \\
\hline 1 & 1 & 2 & & & & & & & & & 3 & & & & & 5 & 1 & 6 & & 9 & 9 \\
\hline 2 & & & & & & 2 & & 1 & & & 3 & & & & 1 & 4 & 1 & 6 & & 9 & 9 \\
\hline 3 & 1 & 1 & & & 1 & & 1 & & & & 4 & & & & & 3 & 2 & 5 & & 9 & 9 \\
\hline 7 & & & & & & & & & & & & & & & & 1 & & 1 & & 1 & 1 \\
\hline 8 & & & & & 1 & & & & & & 1 & & & & & & & & & 1 & 1 \\
\hline 9 & & & & 1 & 1 & 1 & 1 & 2 & 1 & & 7 & 1 & & 1 & & 1 & 2 & 3 & & 11 & 10 \\
\hline 10 & & & 1 & & 1 & & & & & & 2 & & & & & 2 & 1 & 3 & & 5 & 5 \\
\hline 11 & 1 & 2 & 1 & & & 2 & & 1 & & & 7 & & & & & & & & & 7 & 7 \\
\hline 12 & 1 & & 2 & & 2 & & & & & & 5 & & & & & 2 & 1 & 3 & & 8 & 8 \\
\hline$\sum$ & 4 & 5 & 4 & 1 & 6 & 5 & 2 & 4 & 1 & & 32 & 1 & & 1 & 1 & 18 & 8 & 27 & & 60 & 59 \\
\hline
\end{tabular}

OBS: Frentes são: fria; $\boldsymbol{Q}$ é quente; $\boldsymbol{O} \boldsymbol{c}$ é oclusa; $\boldsymbol{S e c}$ é secundária; $\boldsymbol{P o c}$ é próximo do ponto de oclusão.

Partes da frente fria: van é vanguarda, cen é a parte central, ret é retaguarda, ext é extremidade da frente, ond é onda ativa na frente, ina é frente inativa e fraca.

Ciclones: $\boldsymbol{C} \boldsymbol{c}$ é o centro do ciclone nos estágios de onda e de ciclone jovem; $\boldsymbol{C g}$ é a massa de nuvens ciclogenética.

MA são as nuvens dentro de uma massa de ar: $\boldsymbol{C} \boldsymbol{C M}$ é complexo convectivo de mesoescala, $\boldsymbol{S} \boldsymbol{t}$ são nuvens estratiformes dos baixos níveis, $\boldsymbol{C b}$ são nuvens convectivas.

Rar são situações sinóticas raras: $s q$ é setor quente; $R$ é a regeneração de uma frente sobre o sul do Uruguai devido à união com uma massa de nuvens com curvatura anticiclônica. 
observadas para os casos com ondas em frentes frias (Figura 3b), mas o VMP foi quase igual nos anos de El Niño e de La Niña. A QCP e o VMP na frente quente (Figura 3e) e próximo do ponto de oclusão (Figura 3f), no ano de El Nino, foram maiores para as precipitações muito intensas, comparando-se com as precipitações de todas as outras intensidades (excluindo-se, no caso da frente quente, as precipitações fracas).

Nos anos de La Niña e Normal, em geral, foi observada uma diminuição da QDP com o aumento da quantidade de precipitação (Figura 3). Somente no ano de La Niña para as precipitações associadas a frentes oclusas, a QCP não variou muito para as precipitações de diferentes intensidades (Figura 3 d). Para o ano Normal, a QCP associada a passagens de frentes frias (Figura 3 a) foi maior para as precipitações médias e intensas do que para as precipitações fracas e muito intensas. O VMP foi muito alto na extremidade de frentes frias no ano de La Niña (Figura 3c) e baixo nos casos das precipitações associadas a nuvens St em todos os anos analisados (Figura 3i). a)

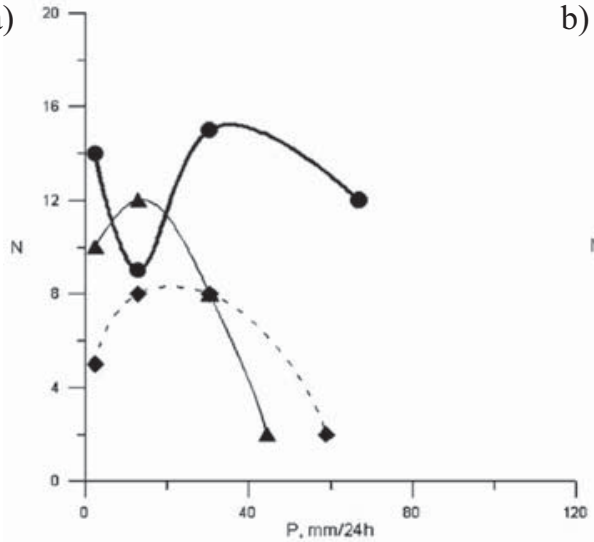

d)

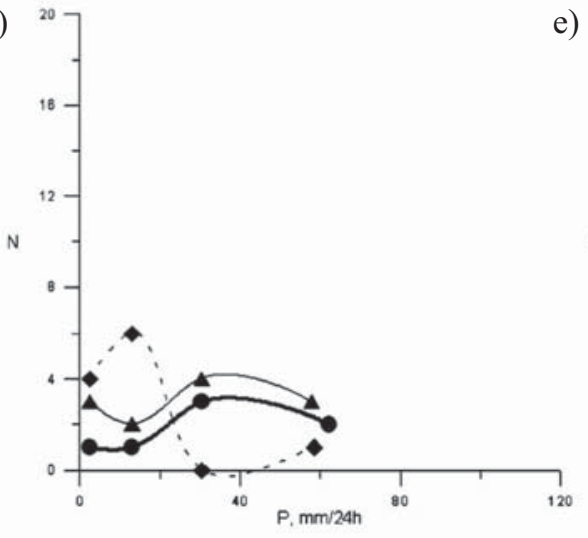

g)

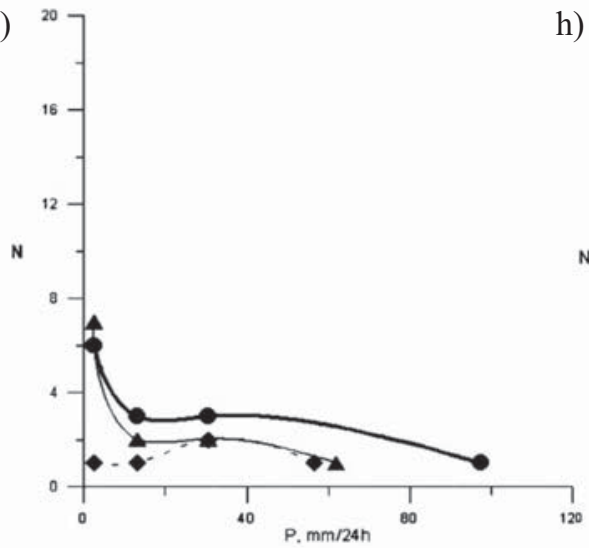

b)

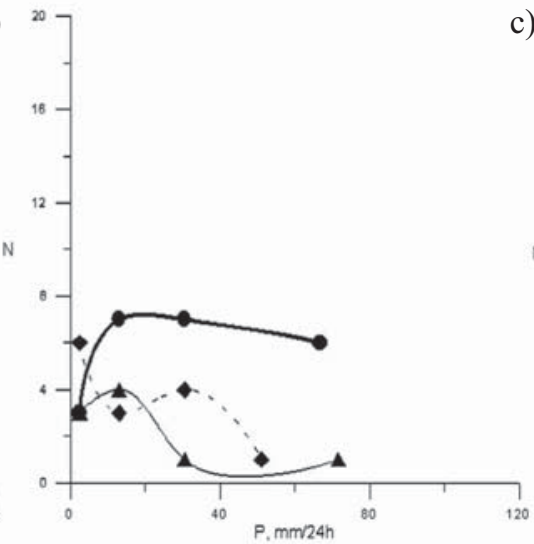

)

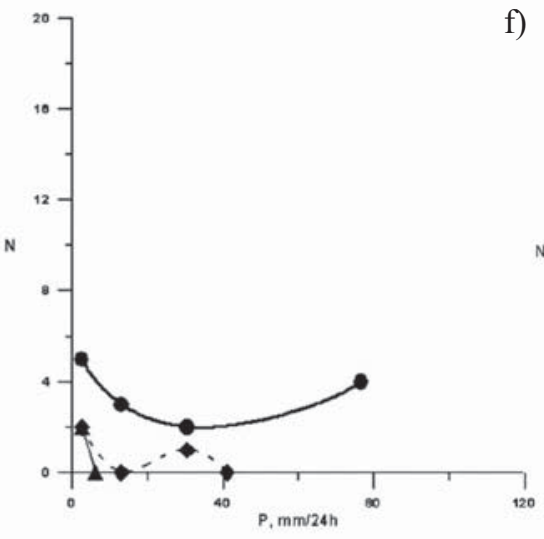

c)
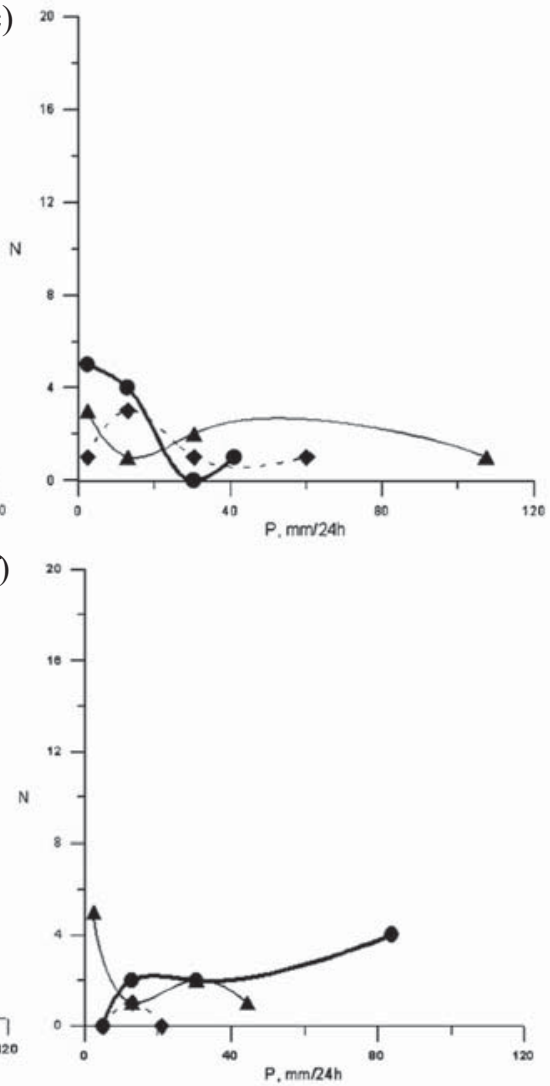

h)

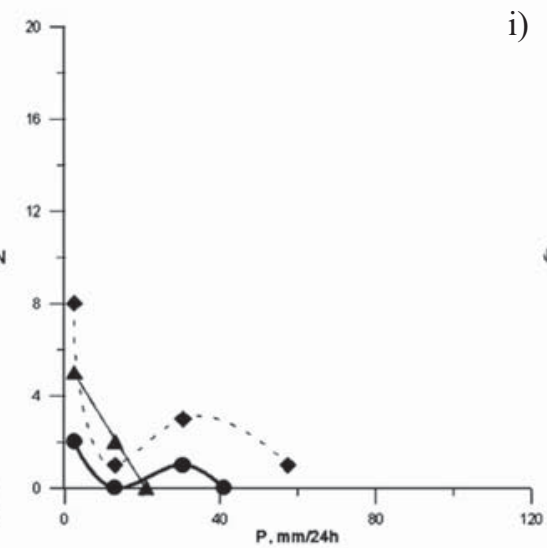

i)

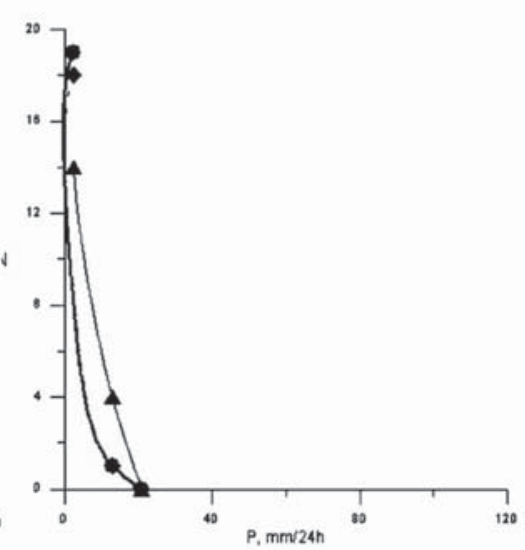

Figura 3 - Distribuição da quantidade de dias $(\mathrm{N})$ com valores médios da precipitação $(\mathrm{P}, \mathrm{mm} / 24$ horas) utilizando todos os casos de cada grupo (precipitações muito intensas, intensas,médias e fracas) nos anos de La Niña ( $\Delta-$-) de El Niño (•—) e Normal ( ------). A precipitação estava associada aos seguintes sistemas e situações sinóticas: a) $\boldsymbol{c e n}$, b) ond, c) $\boldsymbol{e x t}$, d) $\boldsymbol{O c}$, e) $\boldsymbol{Q}$, f) $\boldsymbol{P o c}$, g) $\boldsymbol{C i c l o n e , ~ k ) ~} \boldsymbol{C b}$, l) $\boldsymbol{S t}$. 
A predominância das precipitações de todas as quantidades associadas às zonas frontais em geral pode ser vista nas mesmas Tabelas 5, 6, 7 e 8. No ano de El Niño a QCP não variou muito com o aumento da quantidade de precipitação; todavia nos anos de La Niña e Normal a QCP diminuiu com o aumento da quantidade de precipitação. Para os casos com nebulosidade nos ciclones jovens ( $\boldsymbol{C}$ e $\boldsymbol{C} \boldsymbol{g}$ juntamente nas tabelas), a QCP diminuiu com o aumento da quantidade de precipitação nos anos de La Niña e de El Niño e quase não variou para o ano Normal.

É interessante notar que a QCP fraca associada às nuvens St atingiu os valores 19 e 14 nos anos de El Niño e de La Niña, respectivamente, e foi maior do que para as nuvens $C b$ em todos os anos (Figuras 3c e 3d). Em geral, foi observado um grande número de dias com precipitações fracas associadas a nuvens St. As precipitações intensas e muito intensas associadas a nuvens $C b$ foram mais freqüentes no ano Normal e mais raras no ano de La Niña.

a)

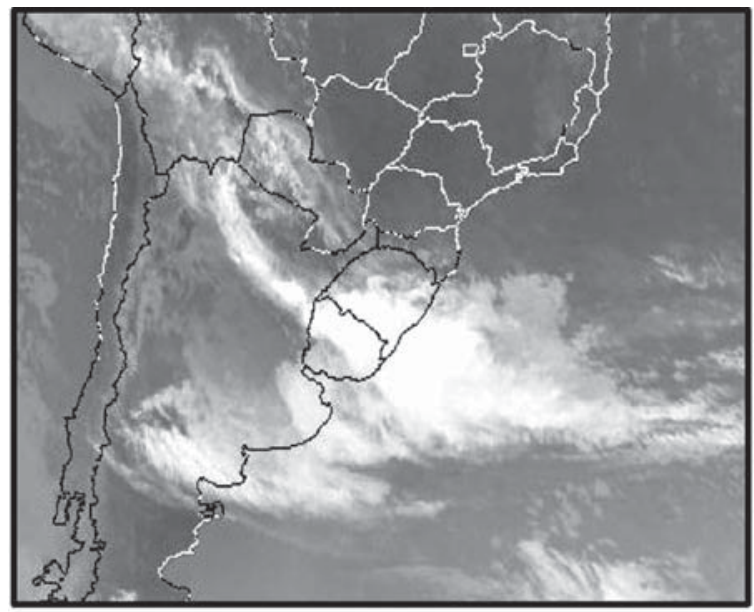

c)

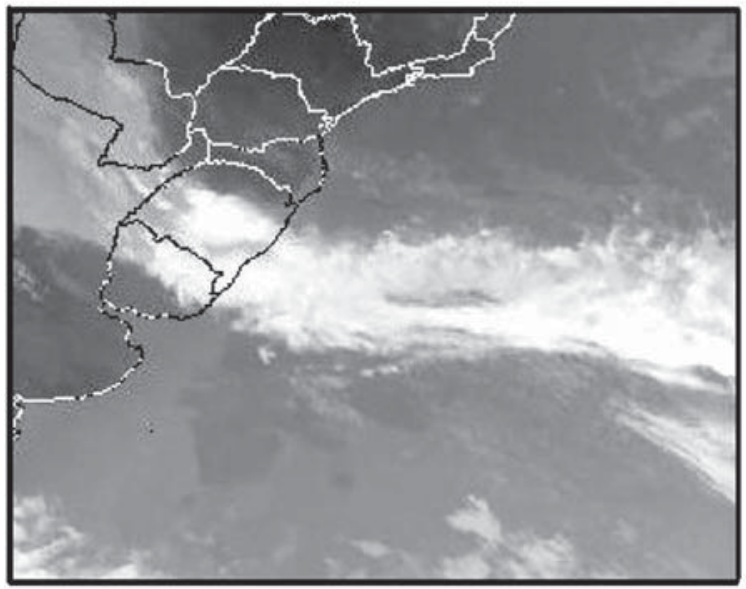

\subsubsection{Exemplos de situações sinóticas associadas a precipi- tações mais intensas do que $100 \mathrm{~mm} / 24 \mathrm{~h}$ em Pelotas}

Como exemplo, apresentam-se imagens de satélite no canal infravermelho para quatro dias com precipitações extremamente intensas ( $>100 \mathrm{~mm} / 24 \mathrm{~h}$ ) em Pelotas (Figura 4).

No dia 22 de dezembro de 1997 (ano de El Niño), na estação Agr foram registradas as precipitações mais intensas do período de estudo, $152 \mathrm{~mm} / 24 \mathrm{~h}$. As precipitações na estação CPMET foram também muito intensas, 52 $\mathrm{mm} / 24 \mathrm{~h}$. Neste dia, perto da cidade de Pelotas, localizou-se um vórtice ciclônico de um ciclone extratropical (Figura 4a). Primeiramente sobre a cidade passou a frente quente deste vórtice, depois a região do ponto de oclusão e, enfim, a frente fria. No mesmo ano, no dia 16 de julho, precipitações maiores do que $100 \mathrm{~mm} / 24 \mathrm{~h}$ (103 mm/24h na Agr e $53 \mathrm{~mm} / 24 \mathrm{~h}$ no CPMET) foram observadas na onda de uma frente fria (Figura 4b).

b)

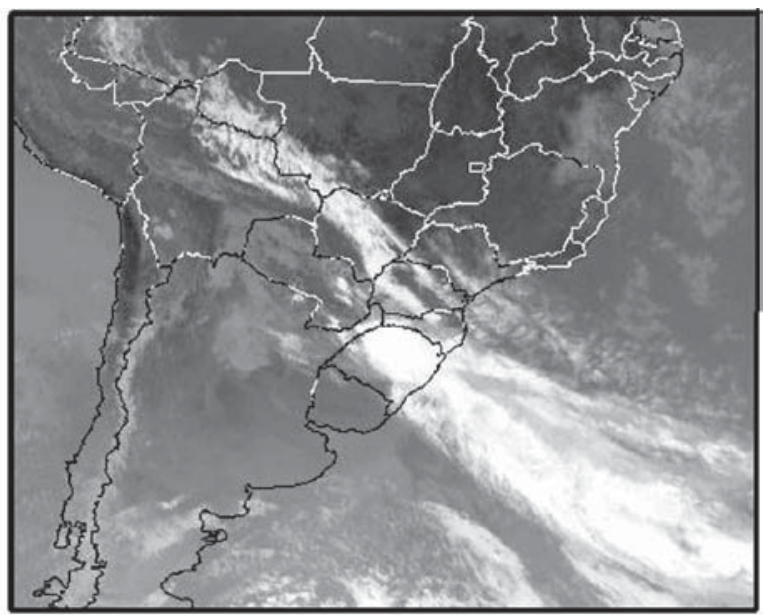

d)

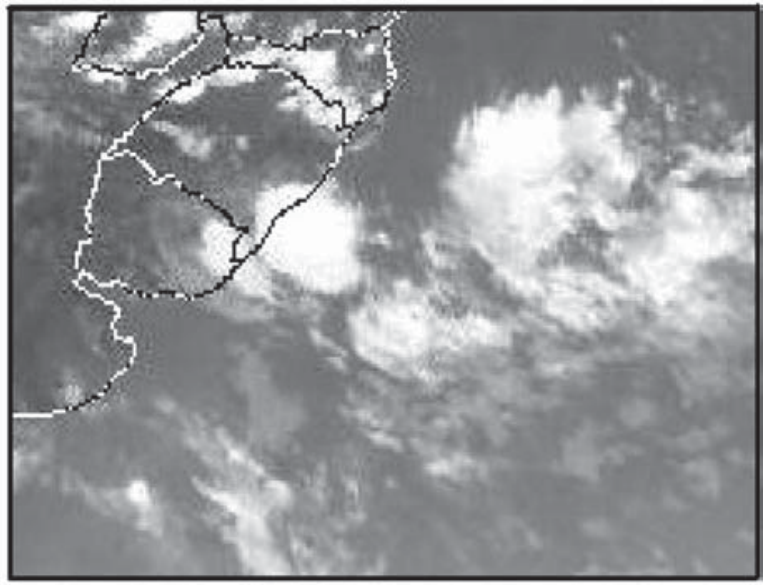

Figura 4 - Imagens de satélite mostrando as situações sinóticas associadas a precipitações mais intensas que $100 \mathrm{~mm} / 24 \mathrm{~h}$ em Pelotas para: a) 22 de dezembro de 1997, 12 UTC; b) 16 de julho de 1997, 15 UTC; c) 25 de agosto de 1998, 18 UTC e d) 13 de fevereiro de 1997,18 UTC. 
No ano de La Niña as precipitações mais intensas foram observadas no dia 25 de agosto de 1998 (107 e $75 \mathrm{~mm} / 24 \mathrm{~h}$ nas estações CPMET e Agr, respectivamente) e foram associadas com a extremidade de uma frente fria (Figura 4c). No ano Normal as precipitações mais intensas atingiram $121 \mathrm{~mm}$ em $24 \mathrm{~h}$ na estação Agr (na estação CPMET, foram registrados $43 \mathrm{~mm}$ em 24h) no dia 13 de fevereiro de 1997 e estavam relacionadas com um CCM (Figura 4d).

Nas imagens relativas aos quatro casos de chuvas muito intensas apresentados, verifica-se que a região de Pelotas encontrava-se sob efeito de convecção intensa, por isso pode ser concluído que a convecção térmica teve um papel muito importante na produção das precipitações registradas.

\subsection{Variações mensais das precipitações associadas a diferentes sistemas sinóticos}

\subsubsection{Variação da precipitação total mensal associada aos diferentes sistemas sinóticos durante os anos de La Niña, de El Niño e Normal}

As curvas da Figura 5 mostram a variação da PTM durante os meses analisados nos anos de La Niña, de El Niño e Normal para cada sistema e situação sinótica. De um modo geral, pode ser visto que a PTM foi maior no ano de El Niño do que para os outros anos nas seguintes situações sinóticas: passagem de frentes frias ( $441 \mathrm{~mm} / \mathrm{mês}$ - Figura 5a) e quentes $(218 \mathrm{~mm} / \mathrm{mês}$ - Figura 5d), próximo do ponto de oclusão $(289 \mathrm{~mm} / \mathrm{mês}$ - Figura 5f). Isto mostra que no ano de El Niño as maiores quantidade de precipitação por mês foram geradas pelas frentes frias e quentes e na região próximo do ponto de oclusão.

Em todas estas situações sinóticas, o pico de PTM foi observado no mês de dezembro. É interessante notar que neste mês foi registrado o valor máximo $\left(4,0^{\circ} \mathrm{C}\right)$ de anomalia positiva da temperatura da superfície do mar (CPTEC, "El Niño"). Nos anos de La Niña e normal para os mesmos sistemas sinóticos não foram registrados picos bem evidentes (Figura 5). Todavia, no ano de La Niña foi registrado um pico de PTM no mês de janeiro, nas situações associadas à passagem de frentes frias (133 mm/mês) e para todas as frentes juntamente ( $220 \mathrm{~mm} / \mathrm{mês}$ ); já para as frentes oclusas, o valor máximo foi observado em dezembro (134 mm/mês). Nos meses de julho e setembro foram encontrados picos de intensidade quase igual (117 e $130 \mathrm{~mm} / \mathrm{mês}$, respectivamente) para os casos de passagem de frentes frias (Figura 5a). Para todas as frentes juntamente, o pico com valores máximos (286 mm/mês), no ano de La Niña, foi observado no mês de agosto (Figura $5 \mathrm{~m}$ ).

A PTM associada as ondas na frente fria (Figura 5c) também foi maior no ano de El Niño do que nos outros anos, ou seja, uma onda em frente fria foi um processo importante para a formação de precipitação neste ano. No ano de El Niño, os valores máximos de PTM associada ao mesmo sistema sinótico foram observados nos meses de julho e de agosto (142 e $141 \mathrm{~mm} / \mathrm{mês}$, respectivamente). No ano de La Niña os valores máximos foram registrados em agosto ( $72 \mathrm{~mm} / \mathrm{mês})$. Nos outros meses os valores de PTM foram baixos; inclusive em setembro e outubro, o valor de PTM para este sistema foi zero.

Um pico com um valor de PTM bem significativo (145 $\mathrm{mm} / \mathrm{mês}$ ), associado à extremidade das frentes frias (Figura $5 \mathrm{~b}$ ), foi observado no mês de agosto do ano de La Nina, ou seja, neste mês significativas somas de precipitação foram geradas por processos nas extremidades das frentes frias. No ano normal este processo foi bastante regular durante quase todos os meses analisados; somente nos meses de outubro, novembro e janeiro não foi registrado nenhum sistema. No ano de El Niño observase um pequeno pico no mês de janeiro.

O valor máximo de PTM (196 mm/mês), associado a frentes oclusas (Figura 5e), foi observado em março do ano de El Niño. No ano de La Niña, o pico de PTM foi menor (134 $\mathrm{mm} / \mathrm{mês}$ ) e foi encontrado em dezembro.

Dois picos de valores de PTM bem significativos, associados a ciclones jovens (Figura 5g), ocorreram em fevereiro do ano de El Niño (179 mm/mês) e em março do ano normal (113 mm/mês). Isto mostra que nestes meses os ciclones jovens tiveram um papel importante para a formação dos valores das precipitações acumuladas.

Não foram registradas variações de PTM associada a nuvens $S t$ durante os meses de todos os anos analisados (Figura 5h) e os valores de PTM foram pequenos. As variações associadas a nuvens $C b$ (Figura 5i) foram mais significativas, principalmente no ano normal. Os valores máximos foram observados nos meses de dezembro e março deste ano (67 e 63 $\mathrm{mm} / \mathrm{mês}$, respectivamente). No ano de El Niño, os valores de PTM foram menores do que no ano normal e ocorreram nos meses de setembro e dezembro.

\subsubsection{Variação da precipitação média associada aos dife- rentes sistemas sinóticos, durante os anos de La Niña, de El Niño e Normal}

A análise de PM mostra que os valores mais altos estão associados a pontos de oclusão (Figura 6f) no mês de dezembro do ano de El Niño ( $96 \mathrm{~mm} / 24 \mathrm{~h}$ ) e a ondas nas frentes frias (Figura 6c) nos anos de La Niña (no mês de agosto, $72 \mathrm{~mm} / 24 \mathrm{~h}$ ) e de El Niño (nos meses de julho e fevereiro, 63 e $71 \mathrm{~mm} / 24 \mathrm{~h}$, respectivamente). Isto significa que os valores das precipitações médias nestes meses foram gerados por pontos de oclusão e ondas em frentes frias. É importante enfatizar que os valores de PTM associados a ondas não foram altos (ver seção 3.3.1), ou seja, as ondas nas frentes frias provocaram precipitações médias intensas para cada caso, mas estes eventos foram raros durante o mês e não contribuíram com somas elevadas de precipitação acumulada durante o mês. 
a)

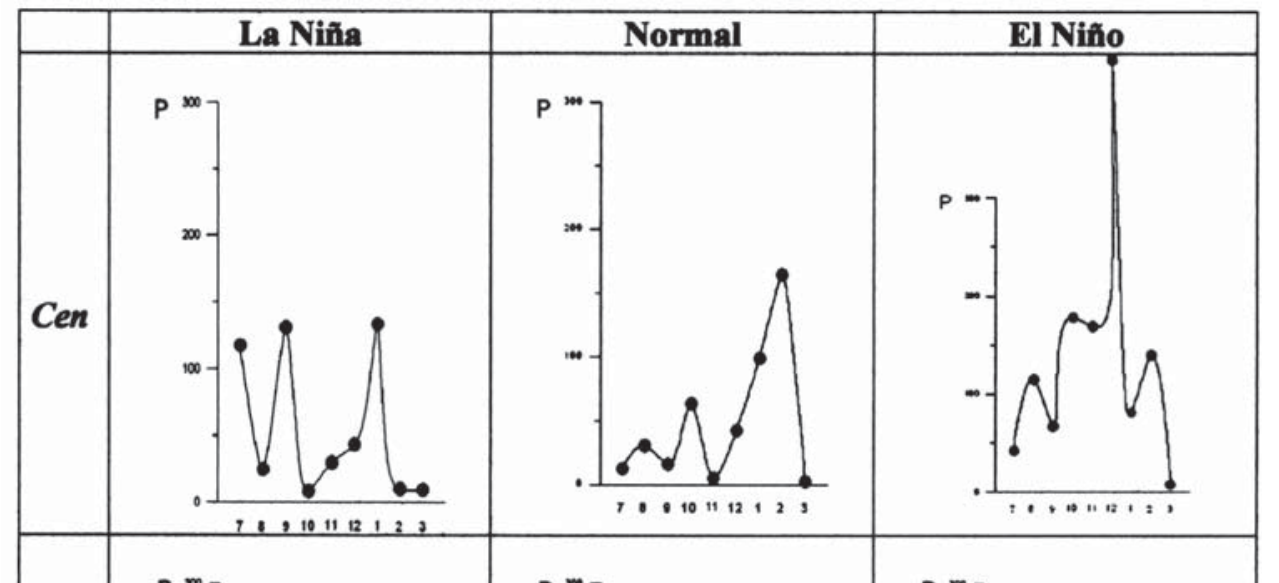

b)

c)

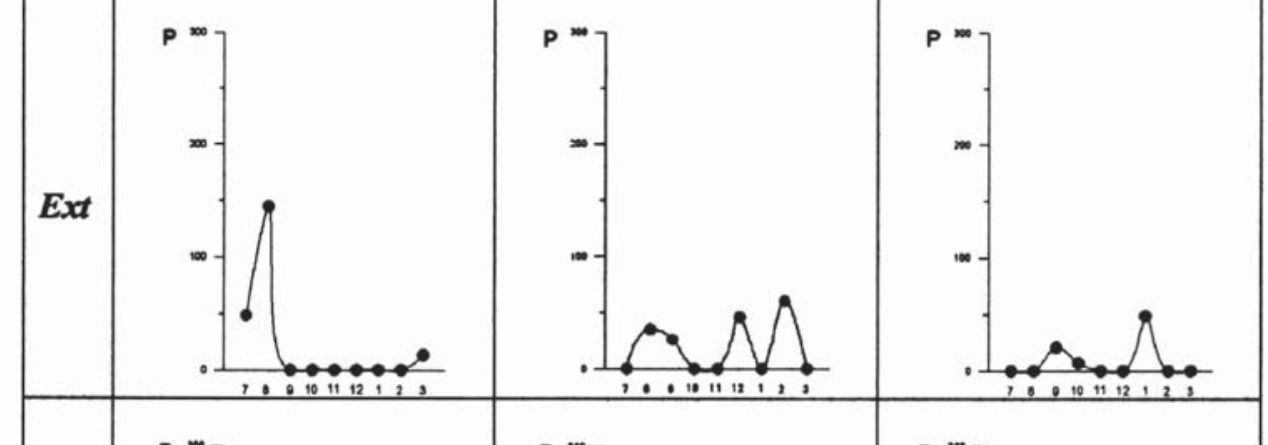

d)

e)

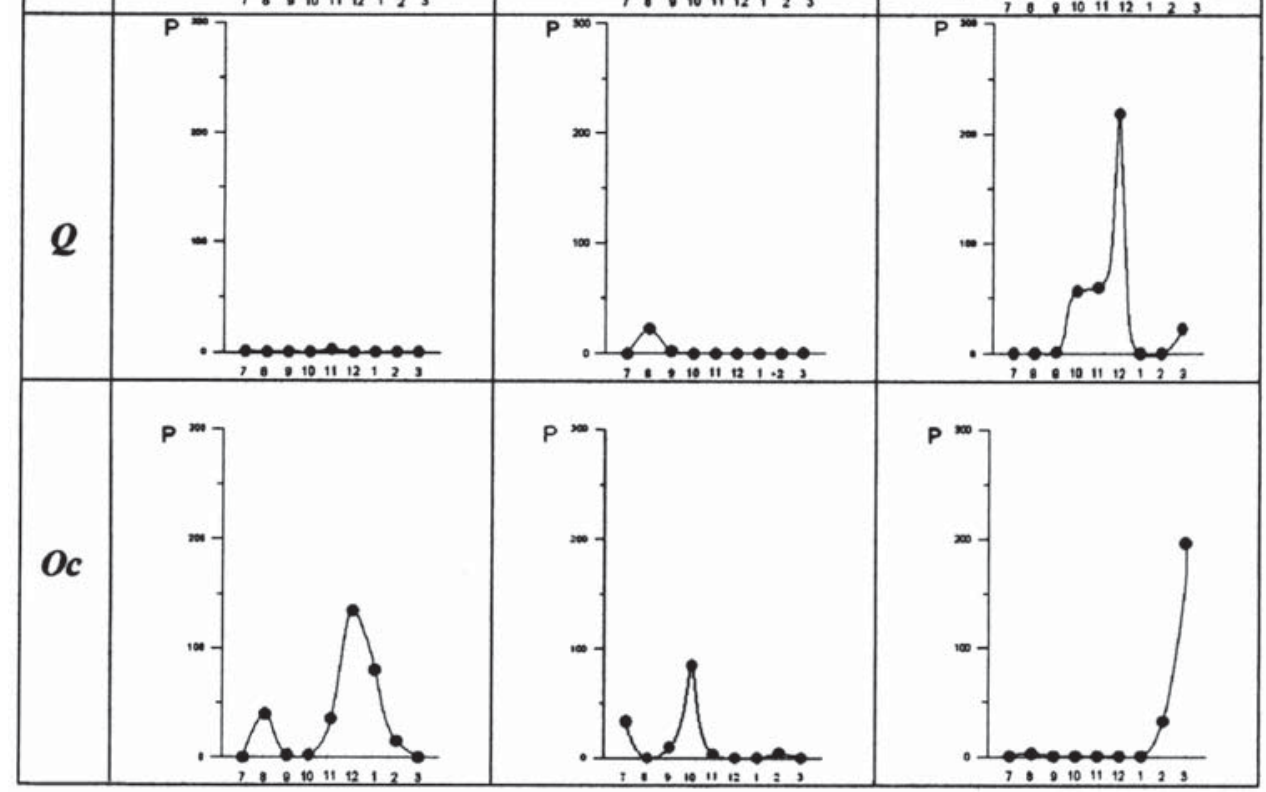

Figura 5 - Variação da precipitação total mensal (mm/mês, eixo Y) durante os nove meses dos anos de La Niña, El Niño e Normal para os sistemas sinóticos associados. No eixo X, os meses são números: 7, 8... 12...3. 
f)

\begin{tabular}{|c|c|c|c|}
\hline & La Niña & Normal & El Niño \\
\hline & & & \\
\hline
\end{tabular}

g)

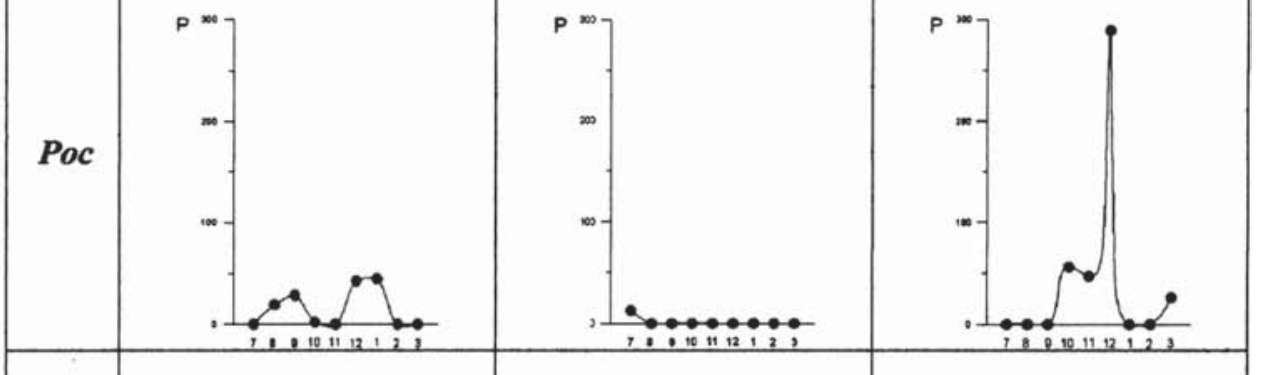

h)

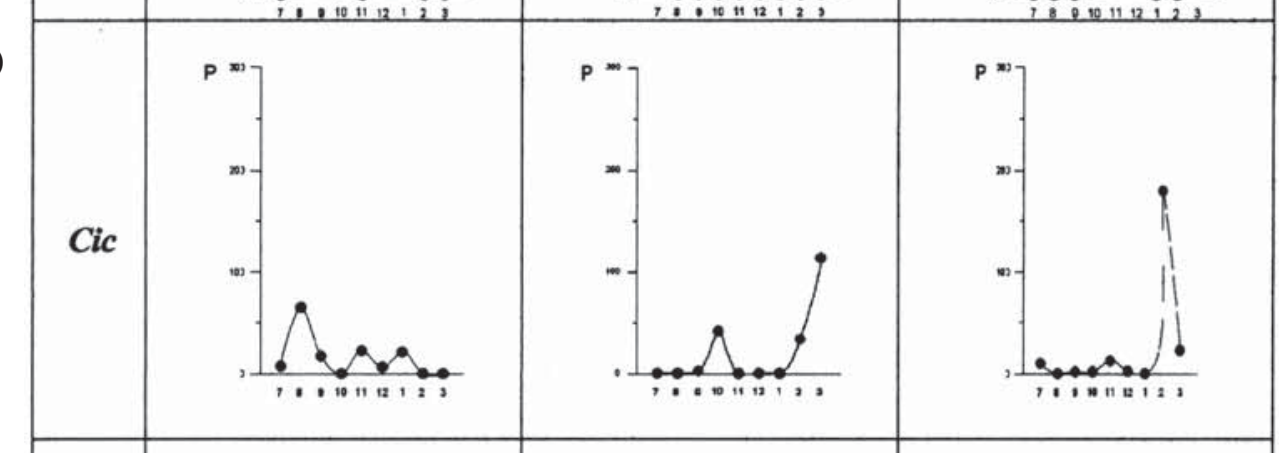

i)

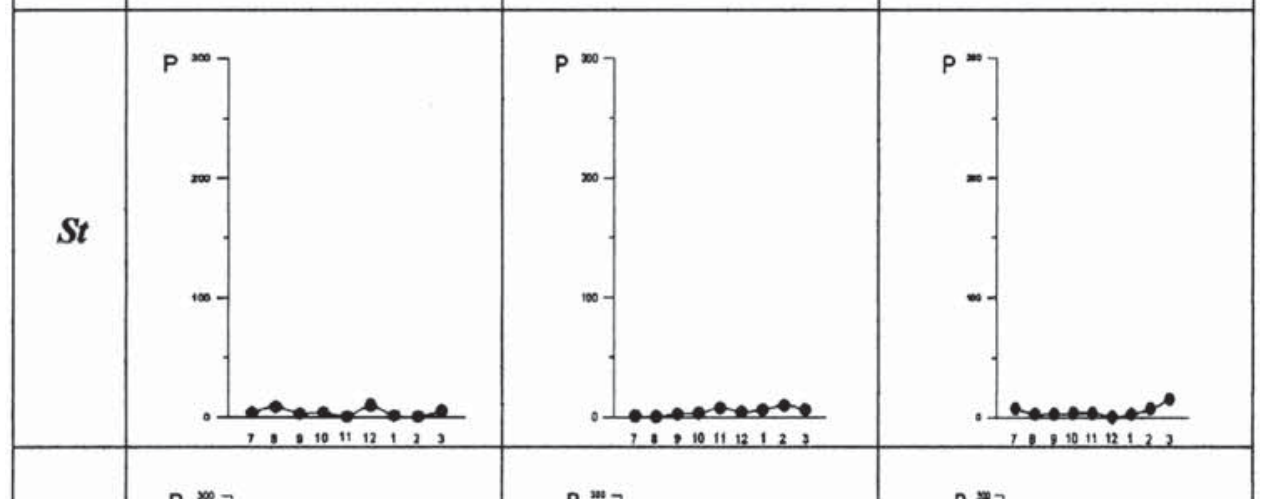

j)

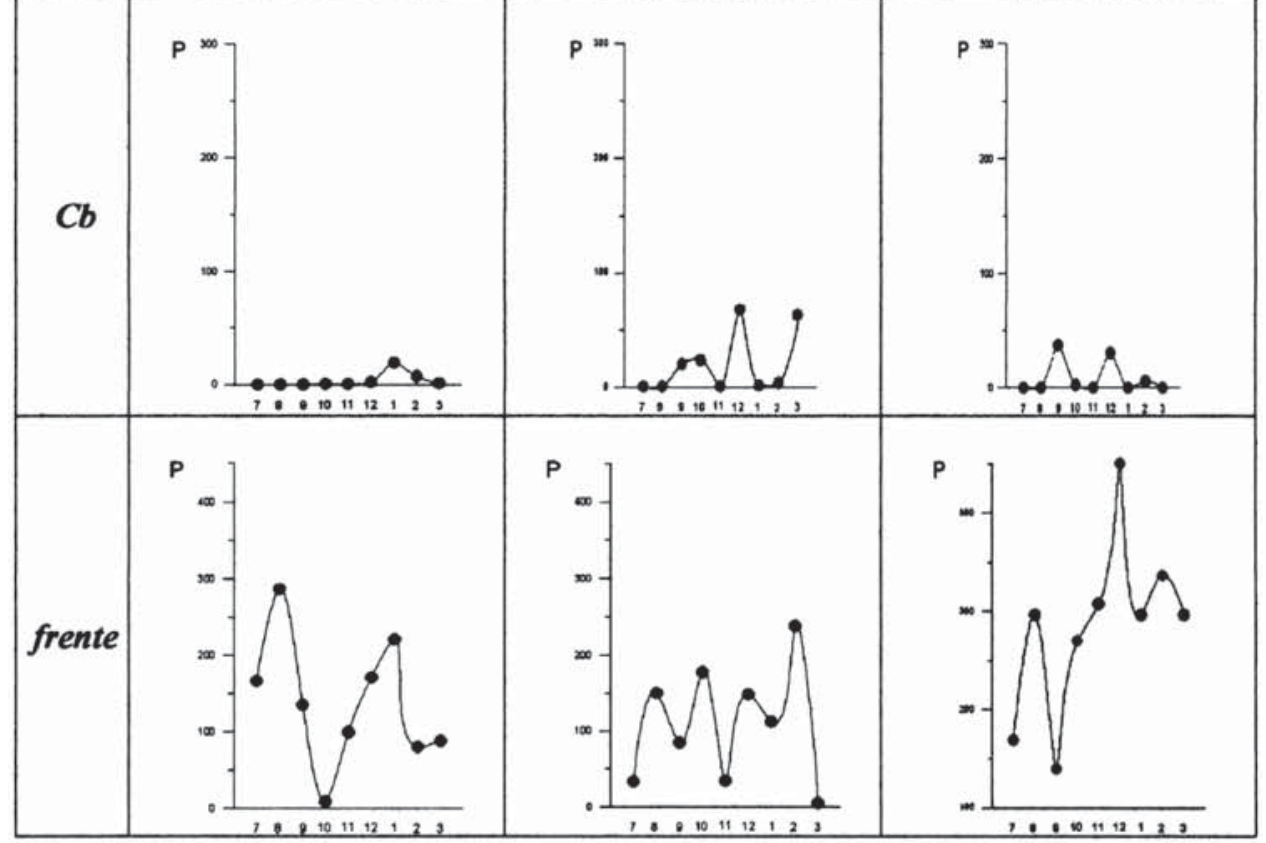

Figura 5 - Continuação 
No mês de dezembro do ano de El Niño foi registrado um pico de PM associado aos mesmos sistemas sinóticos, os quais foram mencionados no primeiro parágrafo da seção 3.3.1, ou seja, foram relacionados às passagem das frentes frias (Figura 6a), quentes (Figura 6d), próximo do ponto de oclusão (Figura 6f) e também para todas as frentes juntamente (Figura 6j). Para cada uma destas situações, no mês de dezembro, foi observado um pico (para todas as frentes juntamente) ou o pico principal (nos outros sistemas mencionados) e, na opinião dos autores, possivelmente estes picos estavam associados com o valor máximo de anomalia positiva da temperatura da superfície do mar (discutido no segundo parágrafo da seção 3.3.1.). a)

b)

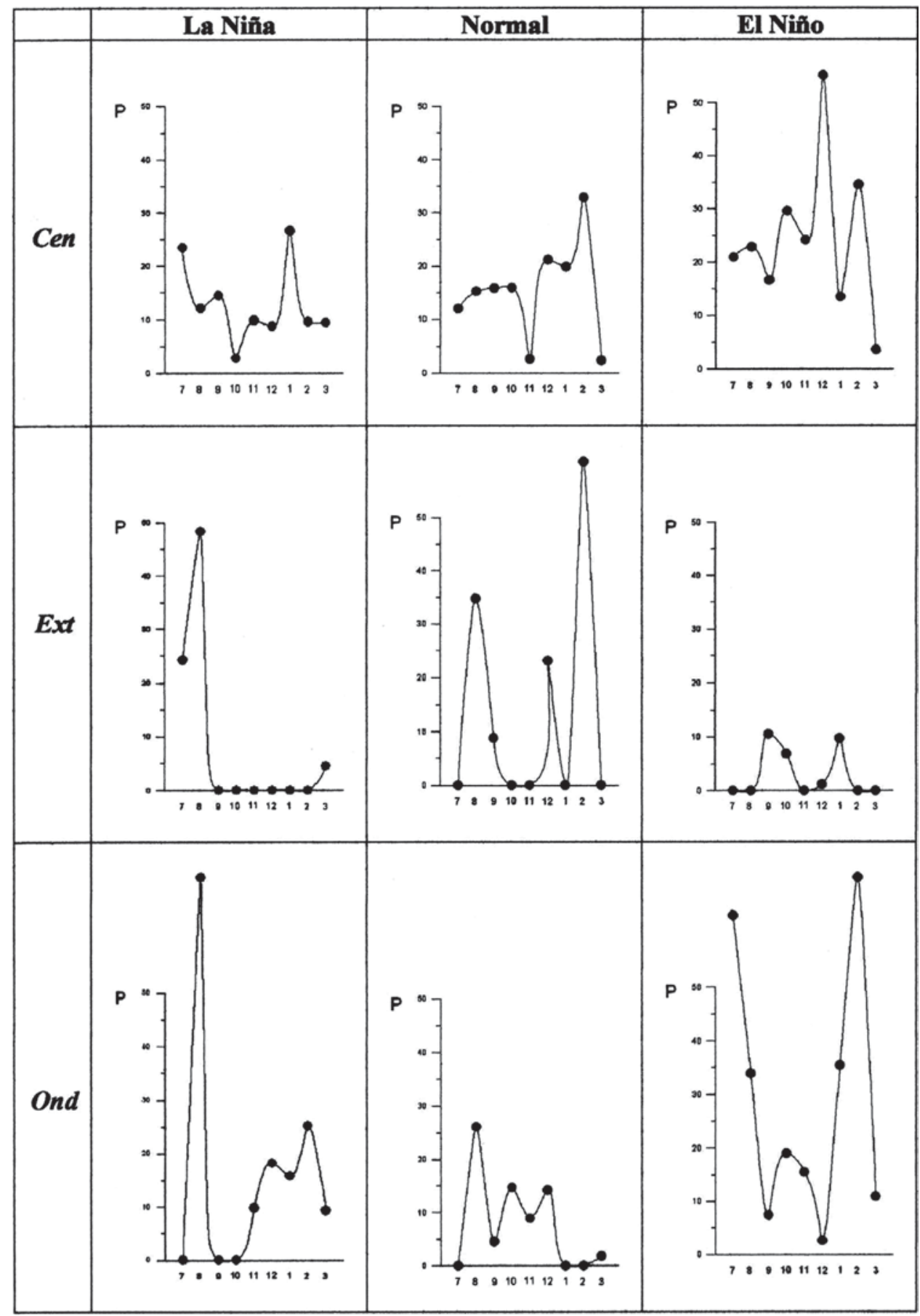

Figura 6 - Variação da precipitação média ( $\mathrm{mm} / \mathrm{mês}$, eixo Y) associada aos sistemas sinóticos durante os nove meses de cada um dos seguintes anos: de La Niña, de El Niño e Normal. No eixo X os meses são números: $7,8 \ldots 12 \ldots 3$. 
No mês de agosto do ano de La Niña foi observado um pico principal de PM associado aos seguintes sistemas e situações sinóticas: extremidade de frentes frias $(48 \mathrm{~mm} / 24 \mathrm{~h}$, Figura 6b), onda em uma frente fria $(72 \mathrm{~mm} / 24 \mathrm{~h}$, como já foi citado no primeiro parágrafo desta seção; Figura $6 \mathrm{c}$ ), ciclone jovem $(32 \mathrm{~mm} / 24 \mathrm{~h}$, figura $6 \mathrm{~g})$ e a frentes em geral $(29 \mathrm{~mm} / 24 \mathrm{~h}$, Figura $6 \mathrm{j}$ ) e um pico secundário foi associado a pontos de oclusão $(19 \mathrm{~mm} / 24 \mathrm{~h}$, Figura $6 \mathrm{f})$ e a frentes oclusas $(20 \mathrm{~mm} / 24 \mathrm{~h}$, Figura 6e). Os picos principais destes dois últimos sistemas sinóticos (44 e $40 \mathrm{~mm} / 24 \mathrm{~h}$, respectivamente) foram registrados em janeiro do mesmo ano. Também em janeiro, um pico de PM foi associado a frentes (frentes em geral - Figura $6 \mathrm{j} \mathrm{e} \mathrm{a}$ passagem de frentes frias - Figura 6a). Os dados do CPTEC (CPTEC, "La Niña”) mostram que no mês de agosto de 1998 teve início o fenômeno La Niña. $\mathrm{O}$ valor da anomalia negativa de temperatura da superfície do mar aumentou de $-0,2{ }^{\circ} \mathrm{C}$ em agosto para $-1,0^{\circ} \mathrm{C}$ em novembro. Este último valor foi quase constante até janeiro, quando o fenômeno La Niña começou a enfraquecer e os valores de anomalia negativa de temperatura da superfície do mar diminuíram rapidamente até alcançarem $-0,2{ }^{\circ} \mathrm{C}$ em fevereiro. Os picos de PM nos meses de agosto e janeiro do ano de La Niña ocorreram exatamente nos momentos

d)

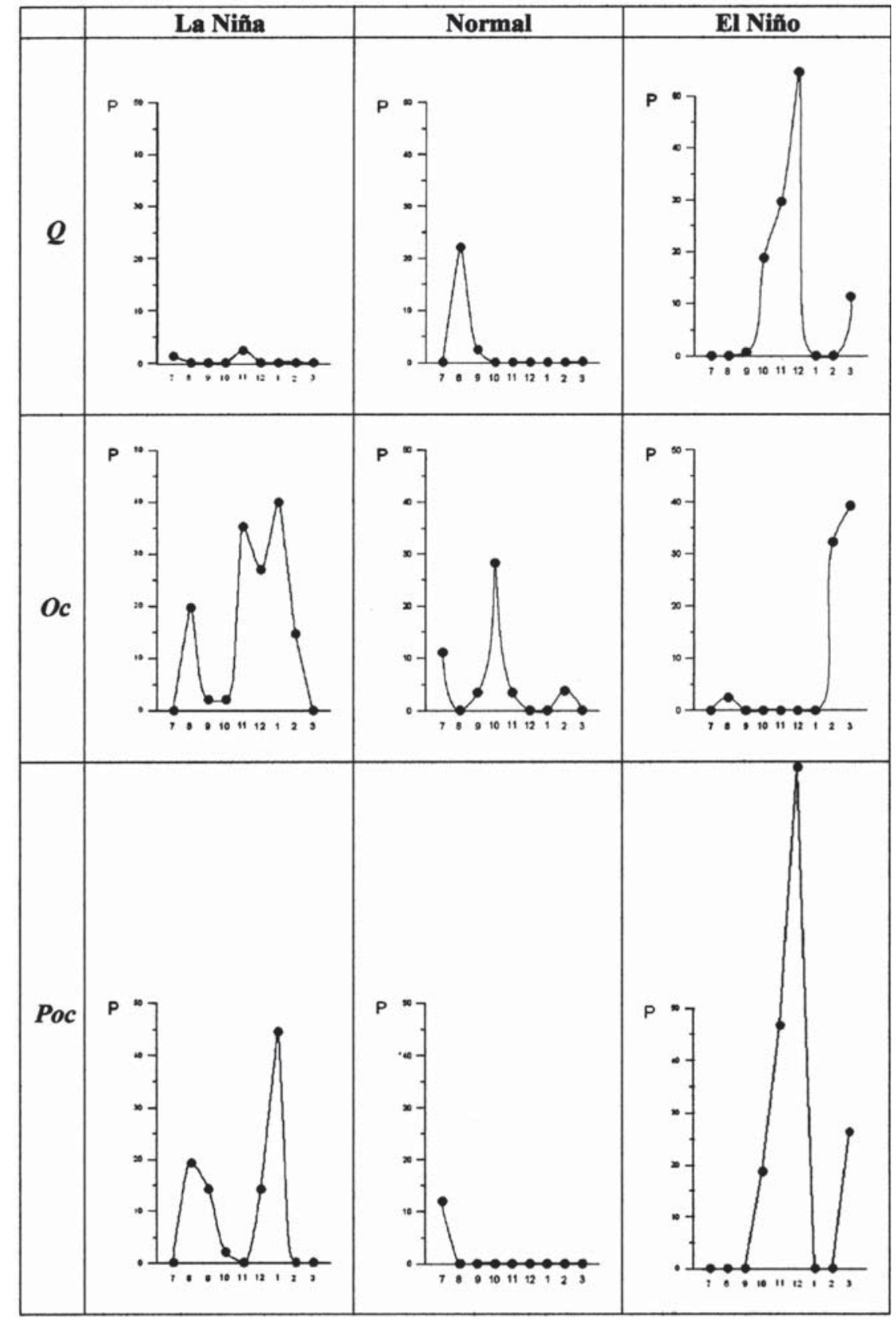

Figura 6 - Continuação 
do início da mudança de valor da anomalia negativa de temperatura da superfície do mar.

No ano normal ocorreram picos de PM no mês de agosto associados às extremidades das frentes frias (pico secundário, $35 \mathrm{~mm} / 24 \mathrm{~h})$, às ondas nas frentes frias $(26 \mathrm{~mm} / 24 \mathrm{~h})$, às frentes quentes $(22 \mathrm{~mm} / 24 \mathrm{~h})$ e frentes em geral $(19 \mathrm{~mm} / 24 \mathrm{~h}$, pico secundário) (Figuras 6b, c, d e j, respectivamente). No mês de outubro do mesmo ano foi observado um pico principal de PM nas frentes oclusas ( $28 \mathrm{~mm} / 24 \mathrm{~h}$, Figura $6 \mathrm{e})$ e picos secundários nos ciclones jovens e nas frentes em geral $(21$ e $20 \mathrm{~mm} / 24 \mathrm{~h}$, respectivamente,Figuras $6 \mathrm{~g}$ e j).
Os valores de PM associada a nuvens $S t$ foram pequenos para todo o período de análise (Figura 6h) e não ultrapassaram 4,3 mm/24h nos anos de La Niña e de El Niño e 7,4 mm/24h no ano normal. Os valores de PM para nuvens $C b$ foram muito maiores nos meses de setembro e dezembro do ano de El Niño (37 e $30 \mathrm{~mm} / 24 \mathrm{~h}$, respectivamente) do que no ano normal (com os valores máximos 22 e $21 \mathrm{~mm} / 24 \mathrm{~h}$, respectivamente, em dezembro e março) e no ano de La Niña (com máximo de PM 10 mm/24h em janeiro) (Figura 6i), ou seja, as precipitações médias, geradas por nuvens $C b$ nos meses quentes, foram maiores no ano de El Niño.

g)

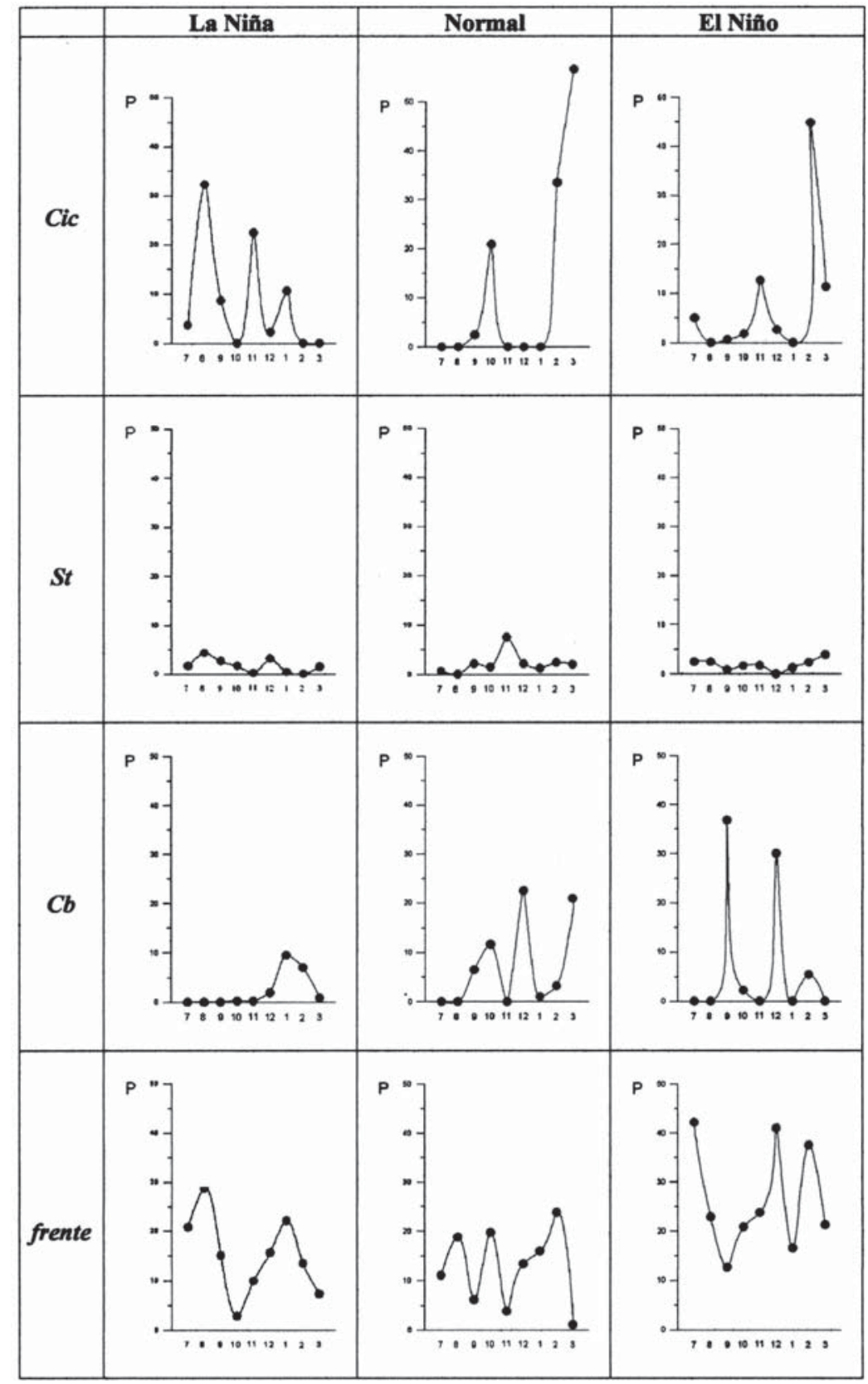

Figura 6 - Continuação 


\section{CONCLUSÃO}

No ano de El Niño, mais freqüentemente do que no ano de La Niña, foram observadas precipitações ligadas a passagem de frentes frias e ondas em frentes frias e, também, a nebulosidade ciclogenética. As precipitações em frentes oclusas e secundárias foram mais freqüentes no ano de La Niña do que no ano de El Niño. As precipitações dentro uma massa de ar foram mais freqüentes nos meses quentes do ano Normal. Dois CCM's que causaram precipitações em Pelotas foram registrados no ano de El Niño e três no ano Normal.

Nos meses associados com a fase ativa dos fenômenos El Niño e La Niña, a quantidade de dias com precipitações associadas a frentes foi muito maior do que no ano Normal.

Os períodos de tempo maiores do que 3 dias consecutivos com precipitações em uma ou nas duas estações incluídas no estudo foram mais freqüentes no ano de El Niño. No mesmo ano o número de Períodos de precipitação com duração de 3, 4 e 5 dias em frentes estacionárias foi muito maior do que no ano de La Niña (11 e 2 Periodos para estes anos respectivamente).

As precipitações muito intensas foram associadas, principalmente, a zonas frontais (passagem de frentes frias, oclusas, ondas nas frentes frias, extremidades de frentes frias) em todos os anos analisados, mas muito mais freqüentemente no ano de El Niño (28 zonas frontais) e mais raramente ( 9 e 5 zonas frontais, respectivamente) nos anos de La Niña e Normal. Em todos os anos, precipitações muito intensas também foram registradas nos ciclones jovens. Além disso, estas precipitações foram registradas mais freqüentemente próximo do ponto de oclusão e nas frentes quentes no ano de El Niño e estiveram associadas a CCM's e a nuvens $C b$ no ano Normal.

As precipitações intensas foram associadas às mesmas situações sinóticas que as precipitações muito intensas e, além disso, à vanguarda de frentes frias. No ano de El Niño estas precipitações também foram observadas em uma massa de nuvens com curvatura anticiclônica, a qual participou na regeneração de uma frente fria. Estas precipitações dentro de uma massa de ar foram registradas, predominantemente, no ano Normal.

As precipitações fracas estiveram associadas com quase todas as situações sinóticas determinadas no estudo. A quantidade de dias com precipitações fracas associadas a nuvens $S t$ variaram de 14 no ano de La Niña a 19 no ano de El Niño.

A precipitação total mensal e a precipitação média de cada evento, associadas à passagem de frentes frias, frentes quentes, próximo do ponto de oclusão e para todas as frentes, foram maiores no ano de El Niño do que nos anos de La Niña e normal. Nestas situações sinóticas foi observado um pico destas precipitações no mês de dezembro, o qual foi associado com o valor máximo $\left(4,0^{\circ} \mathrm{C}\right)$ da anomalia positiva de temperatura da superfície do mar.
Grandes picos de precipitação total mensal foram registrados nos meses de março e fevereiro do ano de El Niño, os quais foram associados a frentes oclusas e a ciclones jovens, respectivamente.

Os picos das precipitações médias foram observados mais freqüentemente nos meses de dezembro e fevereiro do ano de El Niño e nos meses de agosto e janeiro do ano de La Niña; no ano normal, os picos ocorreram preferencialmente nos meses de agosto, outubro e fevereiro.

Os valores e a variação da precipitação total mensal e da precipitação média mensal de cada evento, associados às nuvens $S t$, foram pequenos durante todo o período de análise. A precipitação total mensal associada às nuvens $C b$ foi mais significativa nos meses de dezembro e março do ano normal; todavia, a precipitação média foi mais alta nos meses de setembro e de dezembro do ano de El Niño.

Finalmente, é importante ressaltar que os resultados obtidos neste estudo relatam somente nove meses de um ano de El Niño e de outro de La Niña e no futuro será necessária a utilização de mais anos com ocorrência de cada um destes eventos. Para este tipo de estudo é muito importante a escolha do período de análise. Para esta seleção dos anos de El Niño e de La Niña é preciso levar em consideração vários fatores (o que foi feito no presente trabalho), tais como, intensidade destes fenômenos obtida por diferentes dados, os períodos (meses) exatos do início e do final do fenômeno e, além disso, é preciso escolher os mesmos meses em todos os anos de El Niño e de La Niña. A falta de imagens de satélite anteriores a 1996 nos bancos de dados disponíveis publicamente para utilização ainda não permite elaborar este estudo para muitos anos.

\section{AGRADECIMENTOS}

Os autores agradecem ao Conselho Nacional de Desenvolvimento Científico e Tecnológico (CNPq) pelo financiamento parcial deste trabalho no Centro de Pesquisas Meteorológicas da Universidade Federal de Pelotas e no Instituto de Ciências Atmosféricas da Universidade Federal de Alagoas.

\section{BIBLIOGRAFIA}

ANDERSON, R.K., ASHMAN, J.P., FARR, G. R., FERGUSON, E. W., ISAYEVA, G. N. , OLIVER, V. J., PARMENTER, F. C., POPOVA, T. P., SKIDMORE, R. W., SMITH, A. H., VELTISHCHEV, N. F. The use of satellite pictures in weather analysis and forecasting. Geneva: WMO, Technical note No. 124, 1973, 275p.

CONWAY, E.D. An Introduction to Satellite Image Interpretation.

London: The Johns Hopkins Press. 1997, 242 p. 
CPTEC, "El Niño", Products, <http://www.cptec.inpe.br/ products/elninho/ninho3.gif> Acesso em 23 abr.1999.

CPTEC, "La Niña", Products, http://www.cptec.inpe.br/ products/laninha/nina3.gif $>$ Acesso em

23 abr. 1999.

GOULART, J. P. Distribuição espacial de chuvas intensas na região de Pelotas, RS. Rev. Bras. Meteorol., v. 7, n. 1, p. $553-562,1992$.

FEDOROVA, N. BAKST, L. Identificação da advecção de ar quente através da análise de dados de satélites. Revista Brasileira de Geofísica, v. 17(1), p. 69-81, 1999a.

FEDOROVA, N. BAKST, L. Evolução e velocidade da nebulosidade dos ciclones através de dados de satélites meteorológicos. Rev. Bras. Met.. v.14, n.1, 67-85, 1999 b.

FEDOROVA, N., BAKST, L. Frontal section identification from satellite data. Part I. In: Congresso Brasileiro de Meteorologia 9, 1996, Campos do Jordão, Anais ... v.1, p. 659-663, 1996.

FEDOROVA N., CARVALHO, M. H. Processos sinóticos em anos de La Niña e de El Niño. Parte II: Zonas frontais. Rev. Bras. Met., v.15, n.2, 57-72, 2000.

FEDOROVA, N., CARVALHO, M. H., FEDOROV, D. Formação de vórtices no campo de nebulosidade sobre a América do Sul. Rev. Bras. Met., v. 14, n.2, 15-27, 1999.

FEDOROVA, N., CARVALHO, M. H., SILVA, R. S. Processos sinóticos em anos La Niña e El Niño. Parte I. Vórtices ciclônicos. In: Congresso Brasileiro de Meteorologia 11, 2000, Rio de Janeiro, Anais ... em CD-ROM, 2000a.

FEDOROVA, N., CARVALHO, M. H., SILVA, R. S. Processos sinóticos em anos La Niña e El Niño. Parte V: Regeneração dos sistemas sinóticos. In: Congresso Brasileiro de Meteorologia 11, 2000, Rio de Janeiro, Anais ... em CDROM, 2000b.

FEDOROVA N., KHAN, V. Análise de complexo convectivo de mesoescala sobre o Sul do Brasil. Rev. Bras. Met., v. 14, n.1, 35-48, 1999.

GOULART, J. P. Distribuição espacial de chuvas intensas na região de Pelotas, RS. Rev. Bras. Meteorol., v. 7, n. 1, p. 553 - 562, 1992.
KOUSKY, V. E., CAVALCANTI, I. F. A. Eventos Oscilação do Sul- El Niño: Características, evolução e anomalias de precipitação. Ciência e Cultura, 36 (11), 1888-1899, 1984.

KOUSKY, V. E., CAVALCANTI, I. F. A. Precipitation and atmospheric circulation anomaly patterns in the South American Sector. Rev. Bras. Meteorol., v.3, p.199-206, 1988.

MADDOX, R. A., Large-scale meteorological conditions associated with midlatitude, mesoscale convective complexes. Mon. Wea. Rev., v.111, p. 1475 - 1493, 1983.

OLIVEIRA, A. S. Interações entre sistemas frontais na América do Sul e a convecção na Amazônia. INPE-4008TDL/239, Dissertação (Mestrado em Meteorologia), 134 p., 1986.

PISCIOTTANO, G., DÍAZ, A., GAZES, G., MECHOSO C. R. Rainfall anomalies in Uruguay associated with the extreme phases of the El Niño /Southern Oscillation phenomenon. J. Climate, 7, 1286-1302, 1994.

RAO, V. B., HADA, K. Characteristics of Rainfall over Brazil: Annual Variations and Connections with the Southern Oscillation. Theor. Appl. Climatol. 42. 81-91, 1990.

RAO, P.K., HOLMES, S.J, ANDERSON, R.K., WINSTON, J.S., LEHR, P.E., Weather Satellites: Systems, Data, and Environmental Applications. Boston: American Meteorological Society,503p., 1990.

ROPELEWSKI, C. F., HALPERT, M. S. Global and regional scale precipitation patterns associated with El Niño/Southern Oscillations. Mon. Wea. Rev., v.115, p. 1606 - 1626, 1987.

ROPELEWSKI, C. F., HALPERT, M. S. Precipitation patterns associated with the high index phase of the Southern Oscillation. J. Climate, 2, 268-284, 1989.

SANSIGOLO, C. A., DINIZ, G. B., SALDANHA, R. L. Influência dos eventos El Niño e La Niña no regime de precipitação de Pelotas, RS. Rev. Bras. Meteorol., v. 15, n. 1, p. $69-75,2000$.

SATYAMURTY, P., NOBRE, C.A., SILVA DIAS, P. L. South America. In: Meteorology of the Southern Hemisphere. Boston: A.M.S., v. 27, 1998. p.119-139. 
SEVERO, D. L., GAN, M. A., FERREIRA, N. J. Estudo de um caso de chuvas intensas associado a enchentes na região do Vale do Itajaí, em Santa Catarina. In: CONGRESSO BRASILEIRO DE METEOROLOGIA, 8, Belo Horizonte, 1994. Anais...v. 2, p. 561-564, 1994.

SEVERO, D. L. Estudo de casos de chuvas intensas no estado de Santa Catarina. 1994. 97p. Dissertação (Mestrado em Meteorologia) - Instituto Nacional de Pesquisas Espaciais, São José dos Campos.
SILVA, J. B., AMARAL E. Probabilidades das precipitações pluviométricas em Pelotas, RS. Rev. Bras. Meteorol., v. 2, p. 167 - 177, 1987.

TANAKA, M., NISHIZAWA, T. Interannual fluctuations of the tropospheric circulation and the rainfall in South America. Latin American Studies, 6, 45-61, 1983.

VELASCO, I., FRITSCH, J., M. Mesoscale convective complexes in Americas. J. Geophys. Res., 92, 9591-9613, 1987. 